\title{
GD1a Overcomes Inhibition of Myelination by Fibronectin via Activation of Protein Kinase A: Implications for Multiple Sclerosis
}

\author{
Jing Qin, ${ }^{1}$ Arend H. Sikkema, ${ }^{1}$ Kristine van der Bij, ${ }^{1}$ Jenny C. de Jonge, ${ }^{1}$ Karin Klappe, ${ }^{1}$ Vera Nies, ${ }^{2}$ Johan W. Jonker, ${ }^{2}$ \\ Jan Willem Kok, ${ }^{1}$ Dick Hoekstra, ${ }^{1}$ and Wia Baron ${ }^{1}$ \\ ${ }^{1}$ Department of Cell Biology, University of Groningen, University Medical Center Groningen, 9713 AV, Groningen, The Netherlands, and ${ }^{2}$ Center for Liver, \\ Digestive and Metabolic Diseases, Department of Pediatrics, University of Groningen, University Medical Center Groningen, 9713 GZ, Groningen, \\ The Netherlands
}

Remyelination failure by oligodendrocytes contributes to the functional impairment that characterizes the demyelinating disease multiple sclerosis (MS). Since incomplete remyelination will irreversibly damage axonal connections, treatments effectively promoting remyelination are pivotal in halting disease progression. Our previous findings suggest that fibronectin aggregates, as an environmental factor, contribute to remyelination failure by perturbing oligodendrocyte progenitor cell (OPC) maturation. Here, we aim at elucidating whether exogenously added gangliosides (i.e., cell surface lipids with a potential to modulate signaling pathways) could counteract fibronectin-mediated inhibition of OPC maturation. Exclusive exposure of rat oligodendrocytes to GD1a, but not other gangliosides, overcomes aggregated fibronectin-induced inhibition of myelin membrane formation, in vitro, and OPC differentiation in fibronectin aggregate containing cuprizone-induced demyelinated lesions in male mice. GD1a exerts its effect on OPCs by inducing their proliferation and, at a late stage, by modulating OPC maturation. Kinase activity profiling revealed that GD1a activated a protein kinase A (PKA)-dependent signaling pathway and increased phosphorylation of the transcription factor cAMP response element-binding protein. Consistently, the effect of GDla in restoring myelin membrane formation in the presence of fibronectin aggregates was abolished by the PKA inhibitor H89, whereas the effect of GD1a was mimicked by the PKA activator dibutyryl-cAMP. Together, GD1a overcomes the inhibiting effect of aggregated fibronectin on OPC maturation by activating a PKA-dependent signaling pathway. Given the persistent presence of fibronectin aggregates in MS lesions, ganglioside GDla might act as a potential novel therapeutic tool to selectively modulate the detrimental signaling environment that precludes remyelination.

Key words: fibronectin; ganglioside; multiple sclerosis; oligodendrocyte; remyelination

Significance Statement

As an environmental factor, aggregates of the extracellular matrix protein fibronectin perturb the maturation of oligodendrocyte progenitor cells (OPCs), thereby impeding remyelination, in the demyelinating disease multiple sclerosis (MS). Here we demonstrate that exogenous addition of ganglioside GDla overcomes the inhibiting effect of aggregated fibronectin on OPC maturation, both in vitro and in vivo, by activating a PKA-dependent signaling pathway. We propose that targeted delivery of GDla to MS lesions may act as a potential novel molecular tool to boost maturation of resident OPCs to overcome remyelination failure and halt disease progression.

\section{Introduction}

Multiple sclerosis (MS) is characterized by inflammation, multiple demyelinated lesions, axonal degeneration, and reactive glial

Received Jan. 5, 2017; revised July 7, 2017; accepted July 12, 2017.

Author contributions: J.Q., A.H.S., J.W.K., D.H., and W.B. designed research; J.Q., A.H.S., K.v.d.B., J.C.d.J., K.K., V.N., and W.B. performed research; J.Q., A.H.S., K.v.d.B., J.C.d.J., K.K., V.N., J.W.J., J.W.K., and W.B. analyzed data; J.Q., D.H., and W.B. wrote the paper.

This work is supported by grants from the Dutch MS Research Foundation ("Stichting MS Research"), the Dutch Brain Foundation ("Hersenstichting"), and the Netherlands Organization for Scientific Research (NWO; VIDI and scar formation (Compston and Coles, 2008). Remyelination, involving the regeneration of myelin sheaths and the restoration of functional deficits, is a common feature at early stages of MS, but

Aspasia Grants to W.B.). We thank Charlotte de Jong and Dennis Lentferink for their help with the cuprizone-related experiments and migration assays.

The authors declare no competing financial interests.

Correspondence should be addressed to Wia Baron, Department of Cell Biology, University of Groningen, University Medical Center Groningen, A. Deusinglaan 1, 9713 AV Groningen, The Netherlands. E-mail: w.baron@umcg.nl. DOI:10.1523/JNEUROSCI.0103-17.2017

Copyright $\odot 2017$ the authors $\quad 0270-6474 / 17 / 379925-14 \$ 15.00 / 0$ 
generally fails at later stages, resulting in secondary axonal degeneration and disease progression (Franklin and ffrench-Constant, 2008; Goldschmidt et al., 2009). Current therapies rely primarily on immunomodulating strategies, thereby delaying the time and severity of new lesion formation (Compston and Coles, 2008; Franklin and ffrench-Constant, 2008; Irvine and Blakemore, 2008; Winkelmann et al., 2016). However, these therapies often fail in patients with progressive MS, indicating that once the cascade of events leading to axonal degeneration has been initiated, the suppression of inflammation does not disrupt and/or interfere with clinical disease progression. Hence, the development of treatments that preserve axons by means of remyelination is an essential therapeutic goal.

Remyelination in MS is often insufficient, despite the presence of oligodendrocyte progenitor cells (OPCs) in 70\% of the lesions (Lucchinetti et al., 1999; Chang et al., 2002; Franklin and ffrenchConstant, 2008; Münzel et al., 2013). The failure of OPC maturation can be attributed to numerous factors and may include axonal damage and/or dysregulation of the cellular and extracellular signaling environment within the lesions (Franklin and ffrenchConstant, 2008). Recent progress has highlighted the importance of the aberrant expression of distinct extracellular matrix (ECM) components in the injured environment that contributes to remyelination failure in MS lesions (Back et al., 2005; Lau et al., 2012; Stoffels et al., 2013). Our previous findings revealed that the persistent presence of fibronectin (Fn) aggregates in MS lesions constitutes a most perturbing environmental factor as it impairs OPC maturation and therefore remyelination. Thus, while transiently expressed (dimeric) Fn is a physiologically relevant factor, associated with the regulation of OPC proliferation following CNS demyelination (Stoffels et al., 2015), in MS, Fn aggregation occurs, causing its persistent presence in the lesions, and failure of remyelination is observed (Stoffels et al., 2013). Together, these findings thus prompt for the development of therapeutic approaches, relying on the application of Fn (aggregate) antagonists, capable of overruling the devastating aggregate-induced signaling defect that causes remyelination failure.

It has been well documented that gangliosides, (largely) cell surface localized glycosphingolipids, act as (signaling) modulators of cell functions, including cell growth, apoptosis, and differentiation (Lopez and Schnaar, 2009; Sonnino and Prinetti, 2010). In addition, gangliosides are known to interfere with the interaction of Fn and integrins, their cell surface receptors (Merzak et al., 1995; Wang et al., 2001). Hence, we hypothesized that gangliosides may counteract the perturbing effect of Fn on (re)myelination. Here, we demonstrate that exogenous addition of ganglioside GD1a, but not other gangliosides, eliminates the inhibition of (re)myelination by Fn aggregates via a protein kinase A (PKA)-dependent signaling pathway that promotes OPC maturation. Accordingly, these findings therefore highlight the exciting possibility of considering the application of GDla as a novel tool to promote remyelination in MS lesions.

\section{Materials and Methods}

\section{Cell cultures}

Primary oligodendrocyte cultures. Primary rat OPCs were isolated and cultured as described previously (Bsibsi et al., 2012). OPCs were plated on the indicated substrates [5 $\mu \mathrm{g} / \mathrm{ml}$ poly-L-lysine (PLL), $10 \mu \mathrm{g} / \mathrm{ml}$ plasma Fn (Sigma-Aldrich), or $10 \mu \mathrm{g} / \mathrm{ml}$ aggregated Fn (see below)] and cultured for $2 \mathrm{~d}$ in defined Sato medium (Maier et al., 2005) containing $10 \mathrm{ng} / \mathrm{ml}$ PDGF-AA (Peprotech) and FGF-2 (Peprotech). OPC differentiation was induced by switching to Sato medium containing $0.5 \%$ FCS (Bodinco). Cells at the indicated developmental stage were treated with vehicle (ethanol), gangliosides (10 $\mu \mathrm{M}$, Dr. S. Sonnino, University of
Milan, Milan, Italy), dibutyryl-cAMP (dBcAMP; 1 mM, Sigma-Aldrich), and/or H89 (20 $\mu \mathrm{M}$; Merck Millipore).

Primary dorsal root ganglion neuron-oligodendrocyte cocultures. Dorsal root ganglion neurons (DRGNs) were dissected from 15-d-old Wistar rat embryos and cultured as described previously (Stancic et al., 2012). Fn aggregates $(10 \mu \mathrm{g} / \mathrm{ml})$ were added $1 \mathrm{~h}$ before OPCs were seeded on $16 \mathrm{~d}$ in vitro DRGNs, and gangliosides $(2 \mu \mathrm{M})$ and vehicle (ethanol) were added $1 \mathrm{~h}$ after seeding and at every medium change. OPCs were cocultured with the DRGNs for $14 \mathrm{~d}$ with medium changes every second day.

Organotypic cerebellar slice cultures. Rat organotypic cerebellar slice cultures were generated from neonatal cerebellum as described previously (Miron et al., 2010). Briefly, cerebella were dissected from 1- to 2-d-old Wistar rats and cut into $300 \mu \mathrm{m}$ sagittal sections using a tissue chopper. Slices were plated on Millipore-Millicel-CM culture inserts (Merck Millipore) with four slices per insert. Culture media were composed of 50\% MEM (Invitrogen), 25\% heat-inactivated horse serum (Invitrogen), 25\% Earle's balanced salt solution (Invitrogen), and $6.5 \mathrm{mg} / \mathrm{ml}$ glucose (Sigma-Aldrich). Inserts were transferred into fresh media every 2-3 d. Slices were left untreated to allow the clearance of debris and myelination to occur. To induce demyelination, 21-d-old slice cultures were treated with lysolecithin $(0.5 \mathrm{mg} / \mathrm{ml}$; Sigma-Aldrich) for $17 \mathrm{~h}$ and allowed to recover for $2 \mathrm{~d}$. To induce endogenous aggregation of Fn, demyelinated cultures were treated with the Toll-like receptor 3 (TLR3) agonist polyinosine:polycytidylic acid (poly(I:C); $50 \mu \mathrm{g} / \mathrm{ml} ; \mathrm{GE}$ Healthcare) for $2 \mathrm{~d}$. The next day, slice cultures were treated with gangliosides $(10 \mu \mathrm{M})$ or vehicle (ethanol) and at every medium change (every $2-3 \mathrm{~d})$ for $21 \mathrm{~d}$.

\section{Cuprizone-induced demyelination}

Animal protocols were approved by the Institutional Animal Care and Use Committee of the University of Groningen (Groningen, The Netherlands). Nine-week-old male C57BL/6 mice (Harlan Laboratories) received a stereotactically placed intracranial cannula (brainlink) located on top of the corpus callosum (coordinates relative to bregma: anteroposterior $-0.94 \mathrm{~mm}$; lateromedial $-0.80 \mathrm{~mm}$; dorsoventral $-1.55 \mathrm{~mm}$ ) under isoflurane anesthesia. The mice received perioperative and postoperative analgesia for $2 \mathrm{~d}$ with xylocaine and carprofen, respectively. Animals were individually housed and subjected to a $0.2 \%(\mathrm{w} / \mathrm{w})$ cuprizone (Sigma-Aldrich) diet inducing robust and reproducible demyelination of the corpus callosum (Gudi et al., 2014). Animals received a fresh supply of cuprizone-containing food ad libitum on a daily basis. After 5 weeks, the animals received an injection of aggregated Fn $(1.5 \mu \mathrm{g} / 3 \mu \mathrm{l})$ through the cannula and subsequently returned to standard chow. Two and three days after injection of aggregated $\mathrm{Fn}$, vehicle or gangliosides $(10 \mu \mathrm{M})$ were injected through the same cannula $(3 \mu \mathrm{l})$. Animals were killed $5 \mathrm{~d}$ after Fn aggregate injection by means of transcardial perfusion under isoflurane anesthesia with buffered paraformaldehyde solution (4\%). All buffers were pretreated with diethylpyrocarbonate to prevent RNA degradation. The brains were cryosectioned in the coronal plane at $12 \mu \mathrm{m}$ thickness. Demyelination of the corpus callosum was confirmed by Sudan Black ( $0.1 \%$ in $70 \%$ ethanol) for $5 \mathrm{~min}$.

\section{Generation of fibronectin aggregates}

Fn aggregates were generated from primary rat astrocytes as described previously (Stoffels et al., 2013). Briefly, astrocytes were treated with $50 \mu \mathrm{g} / \mathrm{ml}$ poly(I:C) for $48 \mathrm{~h}$ and lysed in water for $3 \mathrm{~h}$ at $37^{\circ} \mathrm{C}$, and the remaining deposits were scraped in DOC buffer [ $2 \%$ deoxycholate, $2 \mathrm{~mm}$ EDTA, and $5 \mathrm{~mm}$ Tris- $\mathrm{HCl}, \mathrm{pH} 7.4$, containing a protease inhibitor cocktail (Complete Mini, Roche)]. Fn aggregates, verified by Western blot, were obtained by centrifugation at $16,300 \times g$ for $30 \mathrm{~min}$ and dissolved in PBS by sonication.

\section{Adhesion assay}

Adhesion assays were performed as described previously (Baron et al., 2014). Non-tissue culture 96-well plates were coated with Fn or PLL. For "masking" experiments, the coating was followed by $1 \mathrm{~h}$ with coating with gangliosides $(10 \mu \mathrm{M})$ or vehicle (ethanol). For "blinding" experiments, OPCs were preincubated with the indicated gangliosides $(10 \mu \mathrm{M})$ or vehicle (ethanol) for $30 \mathrm{~min}$ at $37^{\circ} \mathrm{C}$. OPCs were seeded at a density of 
10,000 cells/well and left to adhere for $1 \mathrm{~h}$ at $37^{\circ} \mathrm{C}$. Adhesion is determined as a percentage of the $100 \%$ adhesion value.

\section{MTT and LDH assay}

Mitochondrial dehydrogenase activity (MTT assay) was measured as previously described (Bsibsi et al., 2012). Briefly, OPCs were seeded into plasma Fn-coated 24-well plates in Sato medium at 50,000 cells/well. At the immature stage ( $3 \mathrm{~d}$ after initiating differentiation), the cells were treated with the indicated gangliosides $(10 \mu \mathrm{M})$ or vehicle (ethanol, ctrl). After $4 \mathrm{~d}$, the cells were incubated for $3-4 \mathrm{~h}$ with MTT $(0.5 \mathrm{mg} / \mathrm{ml}$; Sigma-Aldrich) in Sato medium. The medium was removed, and the MTT formazan crystals were collected in DMSO (Sigma-Aldrich), and the absorption at $520 \mathrm{~nm}$ was determined. In parallel, a commercially available lactate dehydrogenase (LDH) assay kit (Roche) was used to quantify LDH release into the medium from the same cells as used for the MTT assay. To this end, the medium was centrifuged for $7 \mathrm{~min}$ at $7000 \mathrm{rpm}$, and LDH release was assayed according to the manufacturer instructions.

\section{Proliferation assay}

Cell proliferation was measured by determining the incorporation of the thymidine analog bromodeoxyuridine (BrdU), as described previously, with minor modifications (Stancic et al., 2012). Cells were plated in PLLor Fn-coated eight-well chamber slides at a density of 25,000 cells/well. After $1 \mathrm{~h}$, cells were exposed to the indicated gangliosides $(10 \mu \mathrm{M})$ or vehicle [ethanol, control (ctrl)] in the presence of growth factors PDGF-AA $(10 \mathrm{ng} / \mathrm{ml})$ and FGF-2 $(10 \mathrm{ng} / \mathrm{ml})$ and $10 \mu \mathrm{M}$ BrdU. After $16 \mathrm{~h}, \mathrm{BrdU}$ incorporation was detected using a BrdU proliferation detection kit (Roche) according to the manufacturer instructions. Nuclei were stained with DAPI ( $1 \mu \mathrm{g} / \mathrm{ml}$, Sigma-Aldrich). Proliferation is expressed as the percentage of BrdU-positive cells of total (DAPI-stained) cells, with at least 500 cells counted per condition.

\section{Migration assay}

Migration assays were performed in 24-well Falcon transwell cell culture inserts containing membranes with a pore size of $8 \mu \mathrm{m}$, as described previously (Stoffels et al., 2015). Both sides of the transwell membrane were precoated with PLL or Fn. OPCs were plated at 100,000 cells/well and allowed to migrate for $24 \mathrm{~h}$. The upper chamber contained gangliosides $(10 \mu \mathrm{M})$ or vehicle (ethanol, ctrl). Nonmigrated cells were removed with a cotton swab from the top compartment of the chamber. Remaining cells on the bottom of the membrane were fixed with $4 \%$ paraformaldehyde in PBS for 15 min at room temperature. DAPI-stained migrated cells were visualized with a TissueGnostics system, and the number of migrated cells per square millimeter were analyzed using TissueQuest Cell Analysis Software (TissueGnostics).

\section{$\left[{ }^{3} H\right]-G D 1 a$}

Tritium-labeled GD1a ([ $\left.{ }^{3} \mathrm{H}\right]$-GD1a; $\left.1.28 \mathrm{Ci} / \mathrm{mmol}\right)$ was added to cells for 24 or $96 \mathrm{~h}$ before collection. Gangliosides were isolated from the cell pellet as described previously (Senn et al., 1992), spotted onto highperformance thin layer chromatography plates, and separated in $\mathrm{CHCl}_{3} /$ $\mathrm{CH}_{3} \mathrm{OH} / 0.2 \%(\mathrm{w} / \mathrm{v}) \mathrm{CaCl}_{2}(11: 9: 2$, v/v/v). Gangliosides were visualized by exposure to iodine vapor, scraped from the plate, dispersed in an UltimateGold (PerkinElmer) scintillation cocktail, and counted in a liquid scintillation counter (LS 6500, Beckman Coulter). Data are shown as the percentage of total activity.

\section{PamChip peptide array analysis}

Serine/threonine kinase (STK) activity profiles were generated with the STK PamChip peptide microarray system (PamGene International; Eriksson et al., 2014; Shi et al., 2016). Cells were lysed in M-PER Mammalian Extraction Buffer containing phosphatase and protease inhibitors (Thermo Fisher Scientific), incubated on ice for $15 \mathrm{~min}$, and centrifuged at $10,000 \times g$ for $15 \mathrm{~min}$ at $4^{\circ} \mathrm{C}$. The PamChip assay was performed on the PamStation 12 according to manufacturer instructions. In short, the PamChip arrays were blocked with $2 \%$ bovine serum albumin (BSA). The reaction mixture contained $0.4 \mathrm{~mm}$ ATP and $2 \mu \mathrm{g}$ of protein lysate per array supplemented with protein kinase buffer, BSA, and STK antibody mix (FITC-labeled). To account for differences in protein input, signal intensities were normalized to the array mean. After a visual check of correct peptide spot identification, data analysis and quantification were performed using Bionavigator software (PamGene International) and the BRB-array tools version 4.5.0. The Phospho-ELM BLAST tool version 9.0 was applied to determine potential upstream kinases.

\section{PKA activity assay}

OPCs were plated at a density of 350,000 cells $/ 35 \mathrm{~mm}$ Fn-coated dish and allowed to differentiate for $6 \mathrm{~d}$. Cells were exposed to $10 \mu \mathrm{M}$ GD1a and lysed at $4^{\circ} \mathrm{C}$ in MOPS [3-( $n$-morpholino)propanesulfonic acid]-lysis buffer [20 mм MOPS, 5 mm EGTA, 2 mм EDTA, 1\% NP-40, 1 mм DTT, and MS-SAFE protease and phosphatase inhibitor (Sigma-Aldrich)]. The cytosolic fraction was obtained upon centrifugation at 13,000 rpm for $15 \mathrm{~min}$ at $4^{\circ} \mathrm{C}$. The cytosolic fraction $(20 \mu \mathrm{g})$ was subjected to a nonradioactive PKA activity assay (Enzo Life Sciences) according to manufacturer instructions. Protein determination was performed by a DC Protein Assay (BIO-RAD), using BSA as a standard.

\section{Immunocytochemistry}

Monocultures. Cells were cultured in Fn-coated eight-well chamber slides (Nalge Nunc) at a density of 25,000 cells/well, fixed $7 \mathrm{~d}$ after initiating differentiation, and stained for MBP (1:250; catalog \#MCA409S, BIORAD/AbD Serotec; RRID:AB_325004) as described previously (Baron et al., 2014). The cells were analyzed with a conventional fluorescence microscope (ProVis AX70, Olympus). In each experiment, at least 500 cells were scored as MBP-positive or MBP-negative ("differentiation"). In addition, cells bearing MBP-positive membranous structures spread between the cellular processes were identified as myelin membrane forming ("myelination").

Cocultures. Cocultures were fixed and costained for MBP (myelin) and NF-H (axon; 1:5000; Cat\# CPCA-NF-H RRID:AB_2149761, EnCor Biotechnology), as described previously (Stancic et al., 2012), and analyzed by confocal laser scan microscopy (TCS SP2 or SP8 AOBS Microscope, Leica Microsystems) using Leica Confocal Software. The percentage of myelinated axons was calculated using MATLAB software programmed to recognize only linear structures [myelin and axons; i.e., excluding oligodendrocyte (OLG) cell bodies]. In each experiment, three images at $20 \times$ magnifications per coverslip and two to three coverslips per condition were analyzed.

\section{Immunohistochemistry}

Cerebellar slice cultures. Cerebellar slices were fixed for $15 \mathrm{~min}$ in $4 \%$ paraformaldehyde and blocked for $3 \mathrm{~h}$ in block solution $(1 \mathrm{mmol} / \mathrm{L}$ HEPES, $2 \%$ heat-inactivated horse serum, 10\% heat-inactivated normal goat serum, $1 \%$ BSA, and $0.25 \%$ Triton X-100 in PBS). Primary antibodies (anti-MBP and anti-NF-H) were applied for $48 \mathrm{~h}$ at $4^{\circ} \mathrm{C}$. Slices were subsequently incubated with appropriate Alexa Fluor-conjugated secondary antibodies (1:500) overnight at $4^{\circ} \mathrm{C}$. Nuclei were stained with DAPI. Analyses were performed as described for cocultures (see Immunocytochemistry).

Brain tissue. Sections were blocked and permeabilized with PBS containing $5 \%$ normal donkey serum (Olig2) or 5\% horse serum [Ki67/ PDGF $\alpha$ receptor $(\mathrm{PDGF} \alpha \mathrm{R})]$ and $0.3 \%$ Triton X-100. Sections were incubated with anti-Olig2 (1:1000; catalog \#AB9610, Millipore; RRID: AB_10141047) or a mixture of anti-Ki67 (1:800; catalog \#PA5-19462, Thermo Fisher Scientific; RRID:AB_10981523) and anti-PDGF $\alpha$ R (1: 2000; catalog \#AF1062, R\&D Systems; RRID:AB_2236897) diluted in PBS containing $3 \%$ serum overnight at $4^{\circ} \mathrm{C}$, followed by a $2 \mathrm{~h}$ incubation with appropriate Alexa Fluor-conjugated secondary antibodies. Nuclei were visualized by DAPI staining. Myelin was stained with $0.1 \%$ (in $70 \%$ ethanol) Sudan Black solution, which did not interfere with immunofluorescence. Sections were analyzed with a confocal laser scan microscope (SP8 AOBS, Leica). The numbers of Olig2-positive cells of DAPI-stained cells, and the numbers of Ki67-positive/PDGF $\alpha$ R-negative, Ki67positive/PDGF $\alpha$ R-positive, and Ki67-negative/PDGF $\alpha$ R-positive cells at the base of the injection site were manually counted.

\section{In situ hybridization}

The generation and the detection of the DIG-labeled proteolipid protein (PLP) probe are described (Chari et al., 2006; Stoffels et al., 2013). PLP 
mRNA reactivity was assessed in the corpus callosum directly at the base of the injection site. Scores were related to PLP positivity in the corpus callosum well outside the lesion area. At minimum, 100 cells were scored in each assessed area.

\section{Western blot analysis}

Equal amounts of protein were subjected to Western blot analysis as described previously (Bsibsi et al., 2012). The antibodies used are antiCREB-S133 (1:1000; catalog \#9198 also \#9198S and \#9198L, Cell Signaling Technology; RRID:AB_2561044), anti-Fn (1:500; catalog \#AB2033, Millipore; RRID:AB_2105702), anti-MBP (1:100; catalog \#MCA409S, BIO-RAD/AbD Serotec; RRID:AB_325004), anti-actin (1:500; catalog \#A 5441, Sigma-Aldrich; RRID:AB_476744), and appropriate IRdyeconjugated secondary antibodies (1:5000; LI-COR Biosciences). The signals were detected using the Odyssey Infrared Imaging System (LI-COR Biosciences) and analyzed using Scion image software.

\section{Experimental design and statistical analysis}

Details of the experimental design are described in the Materials and Methods section, the Results section, and the figure legends along with the individual statistical analyses and the number of independent experiments or animals $(n)$. For cell and slice culture experiments, independent experiments were performed with newborn rats of different litters. Data are presented as the mean \pm SD. Statistical analysis was performed using a one-sample $t$ test when compared relative to vehicle-treated or control cells or slices (set to $100 \%$ in each independent experiment). When relative values of more than two means were compared, statistical significance was calculated by a one-way ANOVA followed by a Dunnett's post-test. When absolute values of more than two means were compared, statistical significance was calculated by a one-way ANOVA followed by a Newman-Keuls post-test. A $p$ value of $<0.05$ was considered significant. Statistical analysis was performed using GraphPad Prism software.

\section{Results}

Ganglioside GD1a overcomes inhibition of myelin membrane formation by fibronectin

To assess whether gangliosides may act as Fn antagonists by precluding their inhibitory effect on myelination, we first examined the effect of various gangliosides on OPC maturation in primary OLG cultures, which were grown on Fn or inert PLL. To this end, gangliosides were added to immature OLGs (Fig. 1A) and the percentages of MBP-positive cells and those that elaborated myelin membranes, reflecting OLG differentiation and myelin membrane formation respectively, were determined. Consistent with previous work by us and others (Buttery and ffrenchConstant, 1999; Maier et al., 2005; Sisková et al., 2006, 2009; Lafrenaye and Fuss, 2010; Stoffels et al., 2013), OLGs plated on Fn are morphologically immature when compared with OLGs plated on PLL (Fig. $1 B$ ). Thus, an $\sim 60 \%$ reduction was observed in the number of MBP-positive OLGs that form myelin membranes on Fn compared with PLL $(38.3 \pm 5.3 \%$ on PLL vs $15.1 \pm 2.3 \%$ on Fn), while the number of MBP-positive cells was similar on either substrate $(40.7 \pm 5.7 \%$ on PLL vs $38.4 \pm 5.6 \%$ on Fn). Intriguingly, while the extent of differentiation of OPCs remained similar (Fig. 1C), treatment of immature OLGs with $10 \mu \mathrm{M}$ GD1a essentially reversed the Fn-induced inhibitory effect on myelin formation (Fig. $1 D$, black bars; $p=0.049, n=3$ ). In fact, upon GD1a treatment, the number of OLGs forming MBP-positive myelin membranes was very similar to that obtained on PLL $(38.3 \pm 5.3 \%$ on PLL vs $36.2 \pm 6.8 \%$ on Fn plus GD1a). Although a nonsignificant enhancement of myelin membrane formation on Fn was also seen in the presence of GD3, other investigated gangliosides were without any effect, emphasizing the selectivity of the stimulatory effect of GDla. Moreover, the effect of GD1a appears to be specific in conjunction with the presence of Fn, since no apparent effect on myelin formation was seen in cells grown on PLL (Fig. 1C, white bars) or another ECM compound, laminin-2 (data not shown). Notably, the exposure of immature OLGs to GD1b and GT1b slightly reduced the number of myelin membranes on PLL (Fig. 1D; GD1b, $p=0.049$; GT1b, $p=0.013$; $n=3$ ). Importantly, GD1a, but not its precursor GM1, similarly enhanced myelin membrane formation when the cells were plated on aggregated Fn (Fig. $1 E$; nearly significant; $p=0.068$; $n=4)$. The treatment of immature OLGs with $10 \mu \mathrm{M}$ gangliosides was not toxic, as no significant release of cytosolic LDH was observed (Fig. 1F, white bars). Consistently, cell viability, as monitored with an MTT assay, was not affected either (Fig. $1 F$, black bars).

To reveal whether GD1a affects other cell behavioral aspects relevant for OPC recruitment to the demyelinated areas, OPCs were subjected to a BrdU incorporation ("proliferation") and transwell migration assay. As shown in Figure 2, GD1a exposure enhanced OPC proliferation on Fn $(p=0.033, n=3)$ whereas GM1 decreased it ( $p=0.008, n=3)$, while both gangliosides decreased OPC migration (GM1, $p=0.033$; GD1a, $p=0.009$; $n=3)$. In contrast, in the case of cells plated on PLL, neither GM1 nor GD1a hardly affected OPC proliferation compared with the control, while GD1a, but not GM1, slightly enhanced rather than decreased OPC migration. Hence, exogenous addition of ganglioside GD1a to immature OLGs overcomes the inhibition of myelin membrane formation by Fn in OLG cultures, while at the same conditions GD1a treatment of OPCs increases proliferation and decreases migration. This effect appears to be dependent on the presence of Fn, because on PLL GDla hardly affected either myelin membrane formation or proliferation, while OPC migration appeared to be slightly increased rather than decreased.

\section{Ganglioside GD1a overcomes inhibition of (re)myelination by aggregated fibronectin}

To mimic more closely the myelinating conditions, we next examined whether GD1a also overcomes the inhibition of myelination by Fn aggregates in DRGN-OLG cocultures. The addition of aggregated Fn inhibited myelination of the DRGNs (Fig. $3 A, B$; $p=0.0001, n=3$ ), whereas the percentage of myelinated axons increased upon exogenous addition of GD1a, but not GM1. In the absence of aggregated Fn, exposure to either ganglioside was without any effect. To further explore the effect of GD1a in a more in vivo-like environment, we next examined the potential effect of GD1a on Fn-inhibited remyelination in demyelinated organotypic cerebellar slice cultures. As shown in Figure $3 C$ and by others (Miron et al., 2010), at defined conditions lysolecithininduced demyelination can be triggered in these cultures $(p=$ $0.036, n=3$ ), which is eventually followed by remyelination. Exposure to GD1a upon lysolecithin-induced demyelination, slightly enhanced remyelination both at 14 and $21 \mathrm{~d}$ after lysolecithin treatment (Fig. 3D). This is likely due to the fact that Fn expression upon lysolecithin-induced demyelination is only transient (Stoffels et al., 2013), and thus remyelination is also robust in untreated cultures (Miron et al., 2010). Therefore, to expose the cells to the more persistent remyelination-inhibiting Fn aggregates, the demyelinated cerebellar slices were treated with the TLR3 agonist poly(I:C). Transient exposure to poly(I:C) induces astrocyte-mediated aggregation of Fn after lysolecithininduced demyelination and, as the Fn aggregates persist in this case (Fig. 3E), remyelination is blocked (Sikkema AH, unpublished observation; Fig. $3 E-H,{ }^{* *} p=0.0002 ; n=3$ ). Of note, when continuously and subcutaneously applied, poly(I:C) stimulates myelin gene expression and OPC recruitment upon 
A

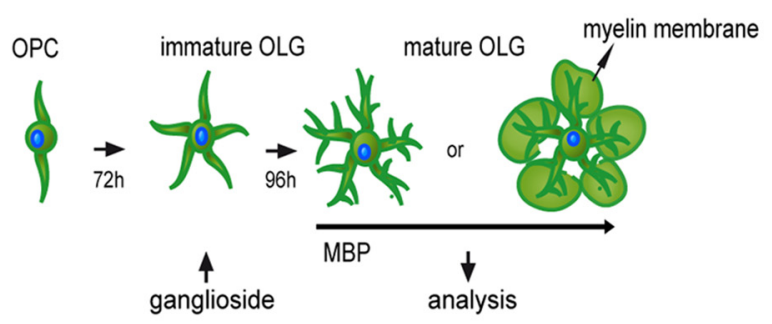

C

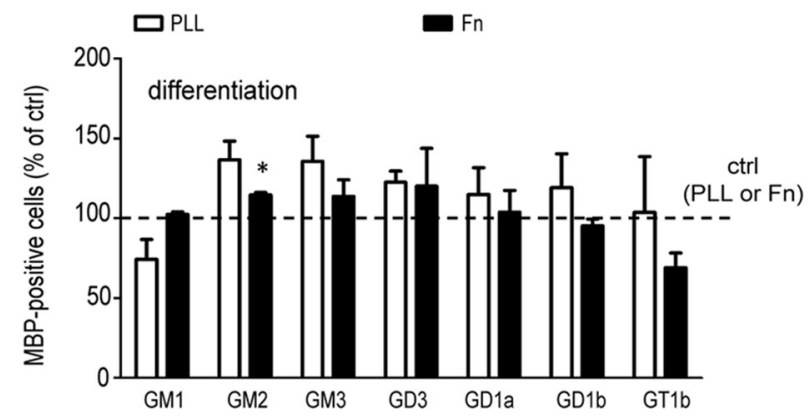

E

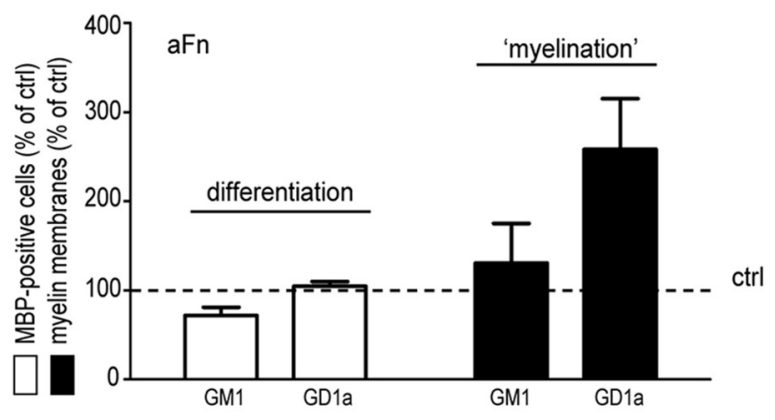

B

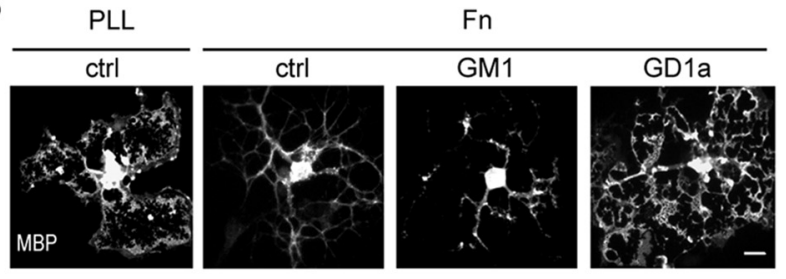

D

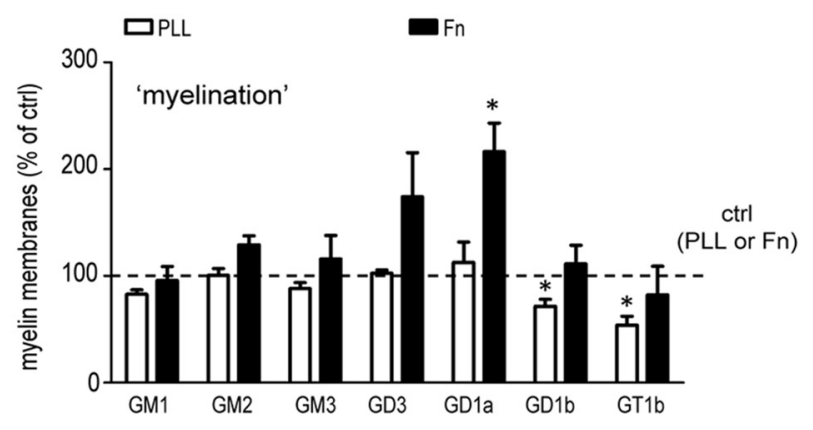

$\mathbf{F}$

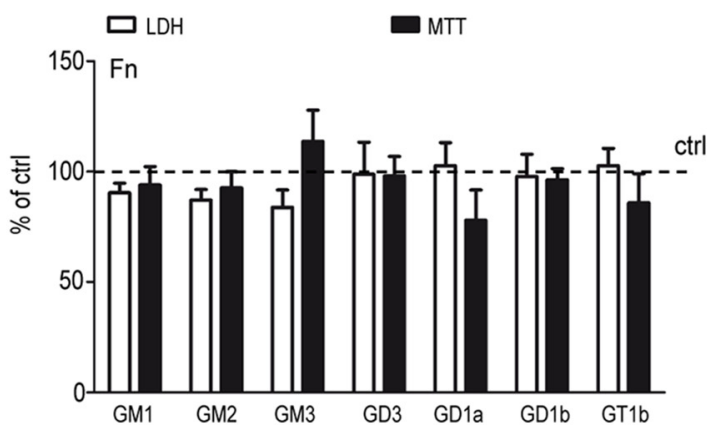

Figure 1. Exogenous addition of GD1a overcomes the inhibition of myelin membrane formation by (aggregated) fibronectin. $A$, Schematic representation of OPC differentiation and myelin membrane formation (myelination) in 0LG monocultures. $\boldsymbol{B}-\mathbf{G}, 0 \mathrm{LGs}$ plated on PLL $(\boldsymbol{B}-\boldsymbol{D})$, plasma $\mathrm{Fn}(\boldsymbol{B}-\boldsymbol{D}, \boldsymbol{F})$, or aggregated $\mathrm{Fn}(\mathrm{aFn} ; \boldsymbol{E})$ were treated at the immature stage $[i . e$., at $3 \mathrm{~d}$ after the initiation of differentiation with vehicle (ethanol, $\mathrm{ctrl}$ ) or with the indicated gangliosides (10 $\mu \mathrm{M})$ ] and analyzed $4 \mathrm{~d}$ after treatment. Representative images of MBP immunocytochemistry of $0 \mathrm{LGs}$ cultured on PLL and Fn $4 \mathrm{~d}$ after treatment are shown in $\boldsymbol{B}$. Scale bar, $20 \mu \mathrm{m}$. The number of MBP-positive cells (differentiation, $\boldsymbol{C}, \boldsymbol{E}$ ), the number of MBP-positive cells bearing myelin membranes (myelination; $\boldsymbol{D}, \boldsymbol{E})$, the effects on cell toxicity (LDH, white bars; $\boldsymbol{F}$ ), and cell viability (MTT, black bars; $\boldsymbol{F}$ ) were assessed $4 \mathrm{~d}$ after treatment. Each bar represents the mean \pm SD of three to four independent experiments. In each experiment, the data of vehicle-treated cells cultured on the respective substrate were set at 100\% (horizontal line). The percentage of MBP-positive cells in vehicle-treated cells cultured on PLL, Fn, and aggregated Fn was $40.7 \pm 5.7 \%(\boldsymbol{C}), 38.4 \pm 5.6 \%(\boldsymbol{C})$, and $39.3 \pm 16.5 \%(\boldsymbol{E})$, respectively. The percentage of MBP-positive cells bearing myelin membranes in vehicle-treated cells cultured on PLL, Fn, and aggregated Fn was $38.3 \pm 5.3 \%(\boldsymbol{D}), 15.1 \pm 2.3 \%(\boldsymbol{D})$, and $29.1 \pm 7.2 \%(\boldsymbol{E})$, respectively. Statistical differences with vehicle-treated cells cultured on their respective substrate, as assessed with a one-sample $t$ test, are indicated ( ${ }^{*} p<0.05, n \geq 3$ ). Note that ganglioside GD1a overcomes Fn-mediated inhibition of myelin membrane formation, while exposure to gangliosides has no effect on cell toxicity and viability.

lysolecithin-induced demyelination in vivo (Natarajan et al., 2016). It is likely that the amount of subcutaneously applied poly(I:C) reaching the lesion may not have sufficed to induce Fn aggregation, thus allowing remyelination to proceed. Following the addition of GDla under Fn-aggregating conditions, the percentage of myelinated axons, a readout for remyelination, was significantly increased compared with vehicle and GM1 treat-

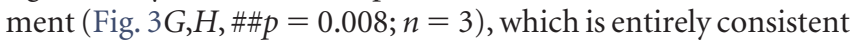
with our observations in monocultures and cocultures. In fact, the effect of GD1a clearly surpasses the level of myelinated axons under control conditions, which may be a result of a GD1amediated enhancement of OPC proliferation in the presence of Fn (Fig. 2A). Hence, these findings strongly support the notion that GDla promotes (re)myelination in the presence of aggregated Fn [i.e., conditions that effectively inhibit (re)myelination in the absence of the ganglioside].
Ganglioside GD1a stimulates OPC proliferation and overcomes inhibition of early OPC differentiation by aggregated fibronectin in vivo

To verify whether the stimulatory effect of GD1a on OPC maturation in the in vitro model systems also applies to in vivo conditions, the effect of GD1a on OPC proliferation and differentiation was investigated in the cuprizone animal model of toxin-induced demyelination-remyelination. Importantly, in contrast to events in OLG monocultures, in vivo Fn aggregates block early OLG differentiation in demyelinated white matter, as evidenced by decreased PLP mRNA levels (Stoffels et al., 2013). The cuprizone model is a highly reproducible toxin-induced animal model of demyelination in the CNS, particularly at the corpus callosum (Gudi et al., 2014). The copper chelator cuprizone induces selective OLG cell death, which results in a maximal demyelination after 5 weeks. Subsequent cuprizone withdrawal leads to recruit- 
A
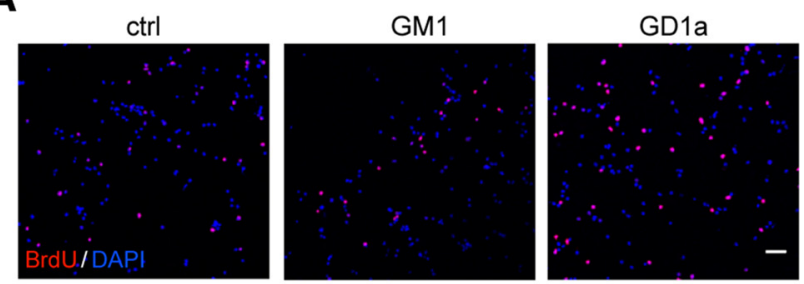

C

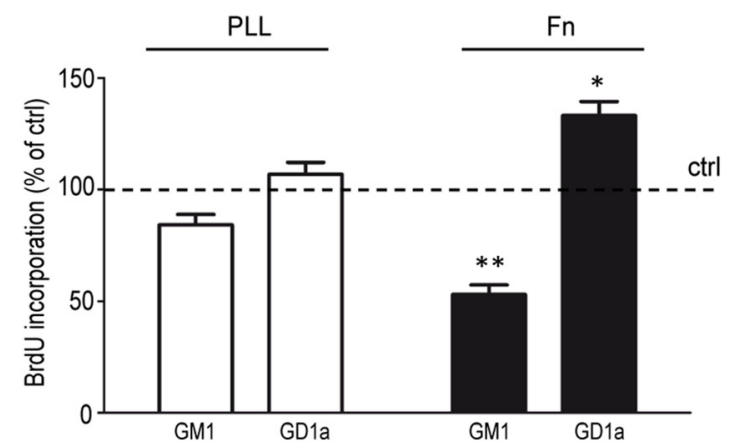

B
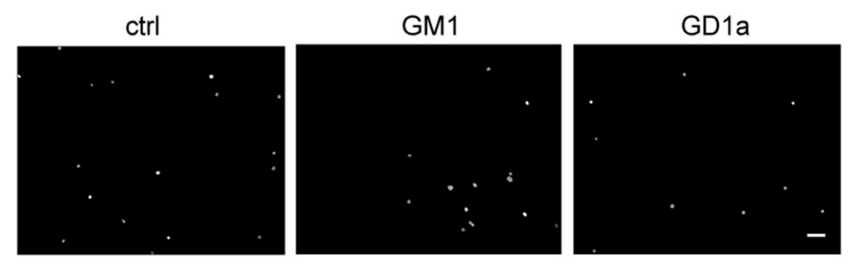

D

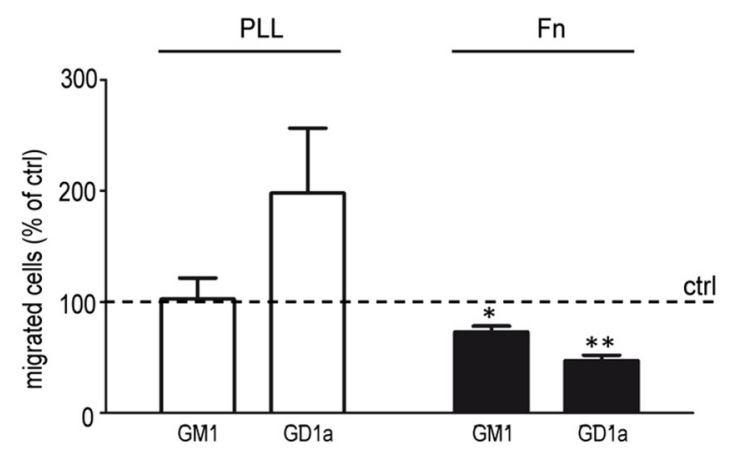

Figure 2. Exogenous addition of GD1a increases the proliferation of and decreases the migration of OPCs on fibronectin. $\boldsymbol{A}-\boldsymbol{D}, 0 \mathrm{OPS}$ plated on either PLL (C, D) or Fn (A-D) were treated with vehicle (ethanol, ctrl) or with the indicated gangliosides (10 $\mu \mathrm{m}$ ), and the effect on OPC proliferation (in the presence of $10 \mathrm{ng} / \mathrm{ml}$ PDGF-AA and $10 \mathrm{ng} / \mathrm{ml}$ FGF-2, $16 \mathrm{~h}$ ) and OPC migration (in the presence of $10 \mathrm{ng} / \mathrm{ml}$ PDGF-AA, $24 \mathrm{~h}$ ) was determined using a BrdU incorporation assay and transwell assay, respectively. Note that the cells were treated and analyzed at the OPC stage. $\boldsymbol{A}, \boldsymbol{B}$, Representative images of proliferation $(\boldsymbol{A})$ and migration $(\boldsymbol{B})$ of OPCs plated on Fn of at least three independent experiments. Scale bar, $50 \mu \mathrm{m}$. $\boldsymbol{C}, \boldsymbol{D}, \mathrm{Quantitative}$ analyses of proliferation $(\boldsymbol{C})$ and migration (D) of OPCs plated on PLL (white bars) or Fn (black bars). Each bar represents the mean \pm SD of three to seven independent experiments. For proliferation, in each independent experiment the percentage of BrdU-positive cells of total (DAPI-stained) cells of at least 500 cells was determined, and the data of vehicle-treated cells (ctrl) were set to $100 \%$ (horizontal line; $\boldsymbol{C}$ ). The number of proliferating vehicle-treated OPCs was $16.5 \pm 6.7 \%$ on PLL and $14.7 \pm 5.9 \%$ on Fn. For migration, in each independent experiment the total number of migrating OPCs (DAPI stained) was determined, and the data of vehicle-treated cells (ctrl) was set to $100 \%$ (horizontal line; $\boldsymbol{D}$ ). The amount of migrating vehicle-treated $0 P\left(s\right.$ was $18.4 \pm 11.6$ cells $/ \mathrm{mm}{ }^{2}$ on PLL and $21.2 \pm 5.5$ cells $/ \mathrm{mm}^{2}$ on Fn. Statistical differences with vehicle-treated cells as assessed with a one-sample $t$ test are indicated $\left({ }^{*} p<0.05,{ }^{* *} p<0.01, n \geq 3\right)$. Note that the ganglioside GD1a increases proliferation, GM1 decreases proliferation, while both gangliosides decrease migration of OPCs plated on Fn.

ment of resident OPCs and almost complete remyelination within 2 weeks (Gudi et al., 2014). Of interest, Fn is transiently upregulated upon cuprizone-mediated demyelination but is not aggregated (Hibbits et al., 2012; Espitia Pinzon et al., 2017). Therefore, aggregated Fn was injected into the demyelinated corpus callosum to create a local MS lesion-like environment (Fig. $4 A$ ). It should be noted that in this in vivo model, in contrast to the organotypic cerebellar slice cultures and MS lesions, the inhibitory effect of the injected Fn aggregates on OPC maturation can be partly overcome in time because of, among other reasons, aggregate clearance. Hence, since a transient Fn aggregate microenvironment is created, only the effect on early OPC differentiation, but not remyelination, can be examined. In this model, vehicle, GD1a, or GM1 was intralesionally injected at days 3 and 4 after Fn aggregate injection (Fig. 4A). Analyses at day 5 revealed that the number of Olig2-positive cells, representing OLG lineage cells, were increased more than twofold upon GDla treatment (Fig. $4 B, C ; p=0.019, n=6)$, but were slightly reduced $(\sim 20 \%)$ in GM1-treated lesions compared with vehicle-treated controls. To assess whether the enhanced Olig2-postive cell numbers were a reflection of increased proliferation, we analyzed the number of proliferating cells using a double-labeling approach with PDGF $\alpha$ R, an OPC marker, and Ki67, a marker for proliferation (Gerdes et al., 1983). GDla-treated lesions showed a significant increase in the number of proliferating (i.e., Ki67-positive, PDGF $\alpha$ Rpositive cells; Fig. $4 D, E ; p<0.0001, n=6$ ). These findings indicate that the increase in Olig2-positive cells is, at least partly, likely to be the result of an increased proliferation. Also, the number of PDGF $\alpha$ R-positive cells was increased in GD1a-treated lesions compared with vehicle- and GM1-treated lesions (Fig. 4D,E; $p=0.004, n=6$ ). Analysis of OPC differentiation by in situ hybridization for PLP mRNA, the major myelin protein, showed a remarkable three times increased expression of PLP mRNApositive cells at the lesion site upon GD1a treatment (Fig. 4D, E; $p=0.0001 ; n \geq 5$ ). In contrast, PLP mRNA-positive cells in both vehicle- and GM1-treated lesions were considerably less prominent. These data thus indicate that GD1a, but not GM1, stimulates OPC proliferation and concomitantly overcomes inhibition of early OPC differentiation in a Fn aggregate-containing cuprizone-demyelinated corpus callosum.

GD1a becomes effective in overcoming fibronectin-mediated inhibition of myelin membrane formation at a relatively late stage of OLG maturation

To clarify the underlying mechanism of GDla, we first assessed whether GD la may interfere with the binding between Fn and its cell surface receptors (integrins) on OLGs. Preincubation of Fn with GD1a reduced the adhesion of OPCs to Fn, but not PLL, by $50 \%$ (Fig. $5 A ; p=0.034, n=3$ ), while the preincubation of OPCs with GD1a reduced the adhesion of the cells on both Fn (Fig. 5B; $p=0.010, n=3$ ) and PLL (Fig. $5 B ; p=0.004, n=3$ ). However, the effect of GD1a appeared to be nonspecific, since GM1 blocked the adhesion of OPCs to Fn in a very similar way (Fig. $5 A, p=$ $0.034, B, p=0.003 ; n=3)$. Accordingly, given the nonspecificity, these data clearly indicate that interference between Fn and its receptors likely does not contribute to the ability of GDla to overcome OPC maturation in a Fn environment. As an alternative, GD1a may activate intracellular signaling pathways. Hence, we examined whether such an effect of GDla might depend on the developmental stage of the OLGs (Fig. 5C). Yet, GD1a is not 
A
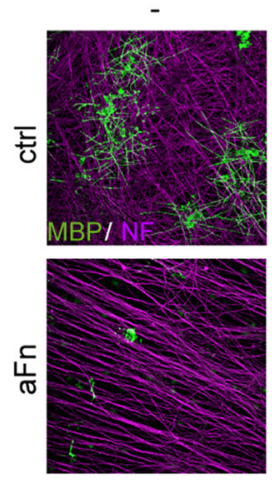

C

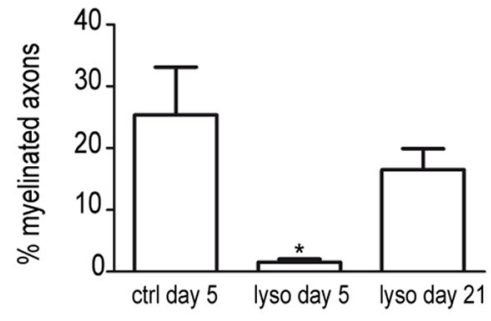

GM1
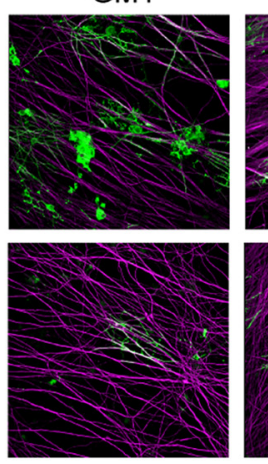

B

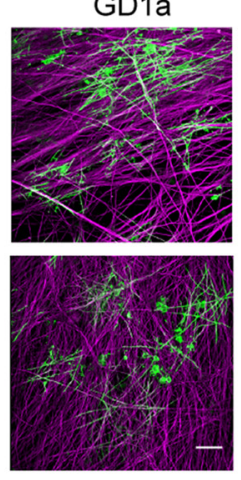

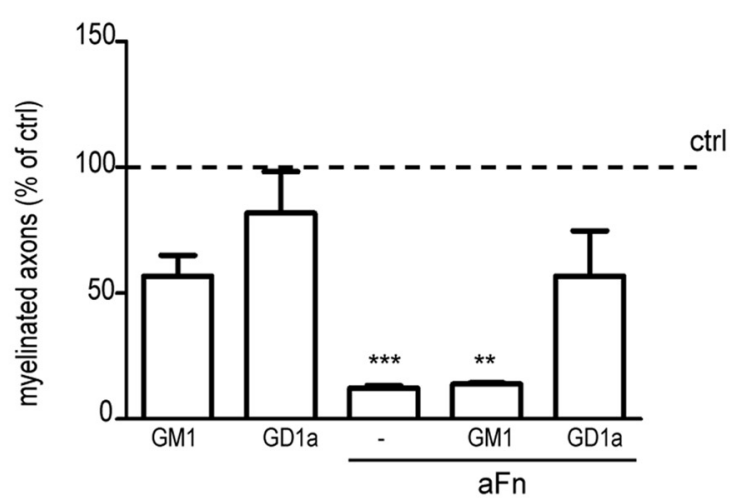

E

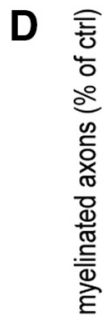
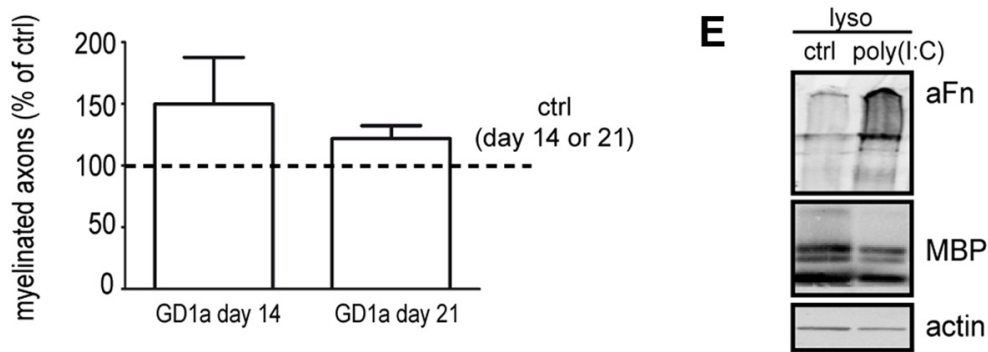

F

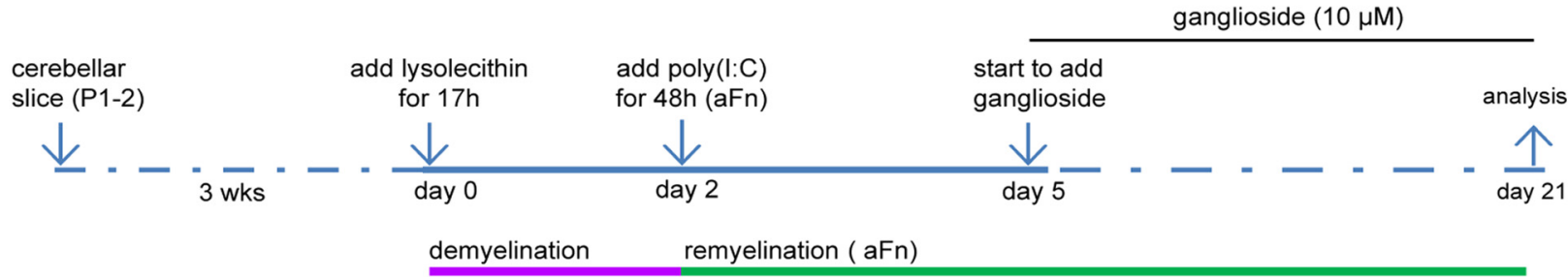

G

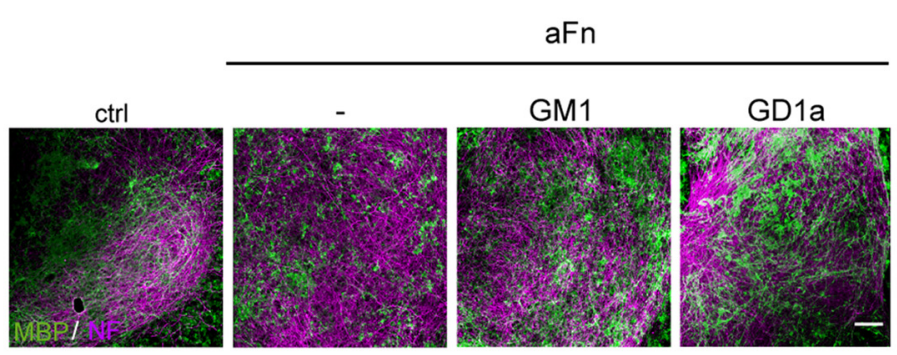

H

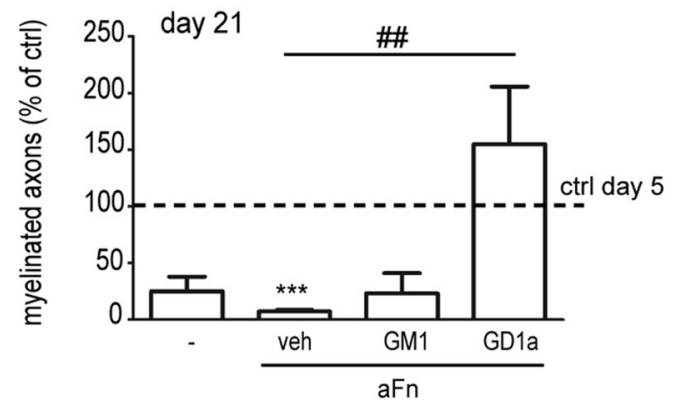

Figure 3. Exogenous addition of GD1a overcomes inhibition of (re)myelination by aggregated DRGN-OLG cocultures and in organotypic cerebellar slice cultures. $A, B, O P C S$ were added to in vitro DRGNs in the absence or presence of aggregated Fn (aFn). DRGN-OLG cocultures were treated $1 \mathrm{~h}$ after plating OPCs with vehicle (veh; ethanol, ctrl in the absence of aFn, - in the presence of aFn) or the indicated gangliosides $(2 \mu \mathrm{m})$ for $14 \mathrm{~d}$. Myelin was visualized with MBP (green) and DRGNs with NF-H (red). Representative images at $14 \mathrm{~d}$ in coculture of three independent experiments are shown in $\boldsymbol{A}$, and quantification in $\boldsymbol{B}$. Scale bar, $50 \mu \mathrm{m}$. The percentages of myelinated axons in vehicle-treated cocultures in the absence of aFn (ctrl) was set at 100\% (horizontal line). The percentage of myelinated axons in vehicle-treated cells was $21.1 \pm 10.6 \%$. Data are represented as the mean $+S D$, and statistical differences with vehicle-treated cocultures, as assessed with a one sample $t$ test, are indicated $\left.{ }^{* *} p<0.01 ;{ }^{* * *} p<0.001, n=3\right)$. Note that ganglioside GD1a overcomes aggregated Fn-mediated inhibition of myelination. $C, D, O$ rganotypic cerebellar slice cultures obtained from newborn rats were cultured for 3 weeks (wks) to allow for myelination. Slices were left untreated (ctrl) or treated with lysolecithin for $17 \mathrm{~h}$ to induce myelination (day 0 ). In $\boldsymbol{D}$, at day 2, demyelinated organotypic cerebellar slice cultures were treated with vehicle (ethanol, ctrl) or with $10 \mu \mathrm{m}$ GD1a for 12 or $19 \mathrm{~d}(n=2)$. The percentage of myelinated axons was assessed $5 \mathrm{~d}$ ( $C$ ), $14 \mathrm{~d}(\boldsymbol{D})$, or $21 \mathrm{~d}(\boldsymbol{C}, \boldsymbol{D})$ after lysolecithin treatment. Data are represented as the mean \pm SD, and for $\boldsymbol{C}$, statistical differences with control cultures at day 5 (C; one-way ANOVA, Newman-Keuls post-test, ${ }^{*} p<0.05, n=3$ ) are shown. $\boldsymbol{E}-\boldsymbol{H}$, A schematic representation of the treatments is indicated in $\boldsymbol{F}$. Organotypic cerebellar slice cultures obtained from newborn rats were cultured for 3 weeks (wks) to allow for myelination. At day 0, demyelination was induced by lysolecithin. At day 2, demyelinated slices were untreated ( - ) or treated with the TLR3 agonist poly(l:C) to induce Fn aggregation [E, Western blot analysis of Fn aggregates (aFn) at day $21, \mathrm{MBP}$ is a mature $0 \mathrm{LG}$ marker, actin is used as a loading control]. Upon Fn aggregation at day 5 , slices were treated with vehicle (ethanol, veh) or the indicated gangliosides $(10 \mu \mathrm{M}$ ) for $16 \mathrm{~d}$. Myelin was visualized with immunostaining for MBP (green) and neurons with NF-H (red) $21 \mathrm{~d}$ after initiating demyelination. Representative images of three independent experiments are shown in $\boldsymbol{G}$; quantification is shown in $\boldsymbol{H}$. Scale bar, $50 \mu \mathrm{m}$. The percentages of myelinated axons in control nondemyelinated cultures at day 5 were set in each independent experiment at $100 \%$ (horizontal line). The mean percentage of myelinated axons at day 5 was $19.5 \pm 5.4 \%$. Data are represented as the mean \pm SD, and statistical differences with control nondemyelinated cultures at day 5 (one sample $t$ test, ${ }^{* * *} p<0.001, n=3$ ) and vehicle-treated aFn-containing demyelinated cultures at day 21 (one-way ANOVA, Dunnett's post-test, \#\#p $<0.01, n=3$ ). Note that ganglioside GD1a overcomes aFn-mediated inhibition of remyelination in organotypic cerebellar slice cultures. 
A

ganglioside $(10 \mu \mathrm{M})$

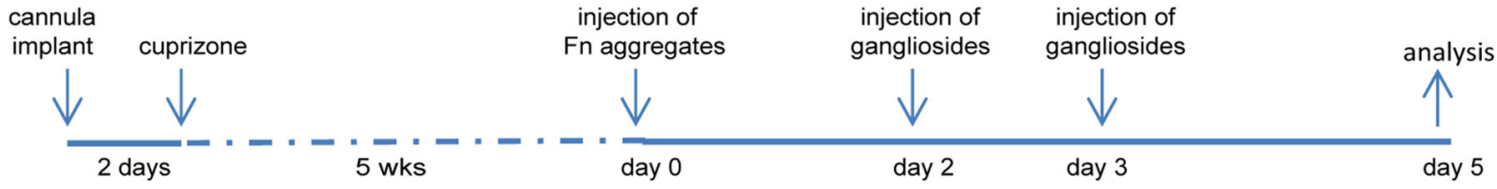

demyelination remyelination $(\mathrm{aFn})$

B
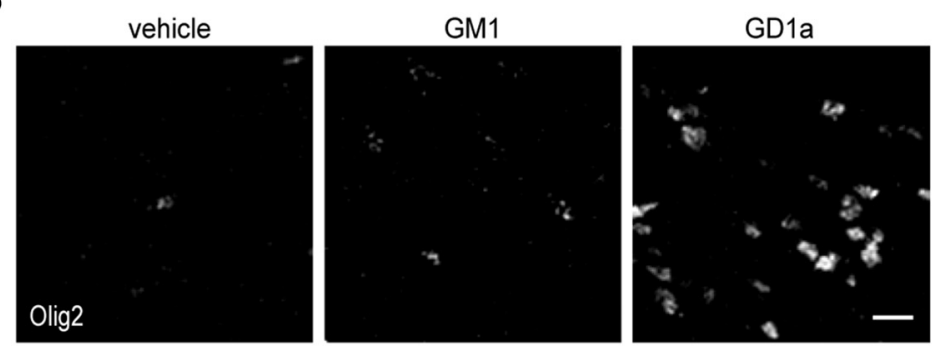

D
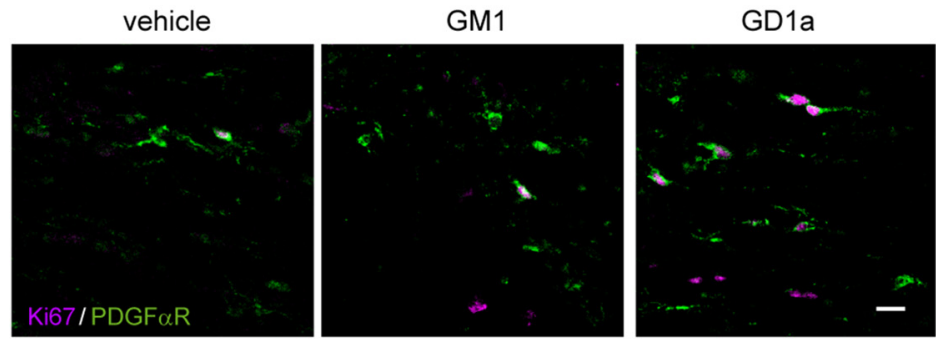

F
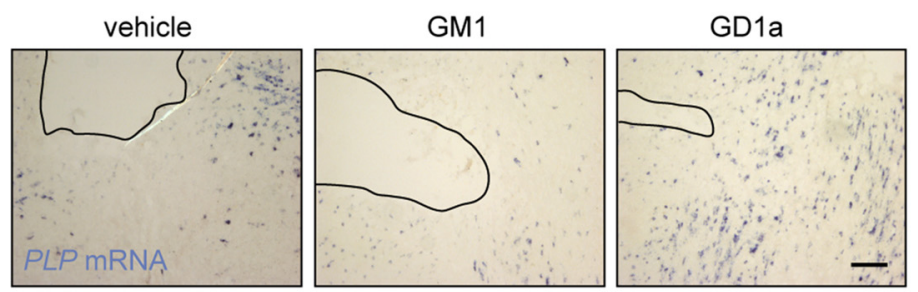

C

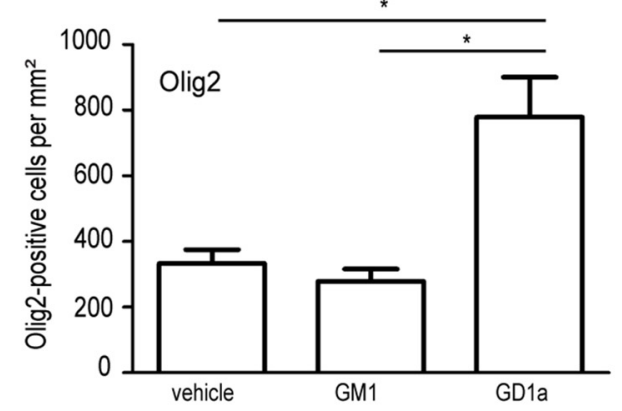

E

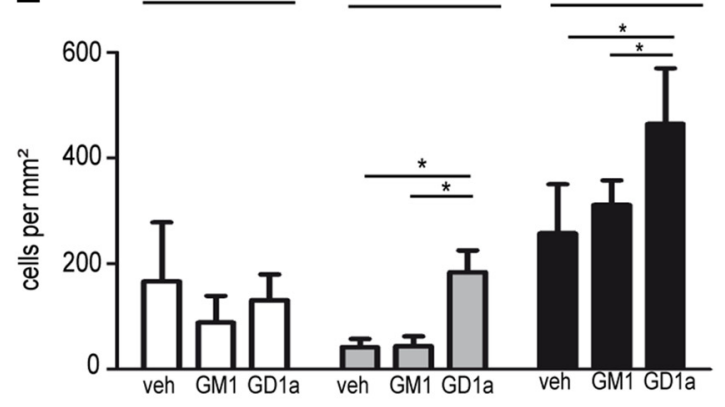

G

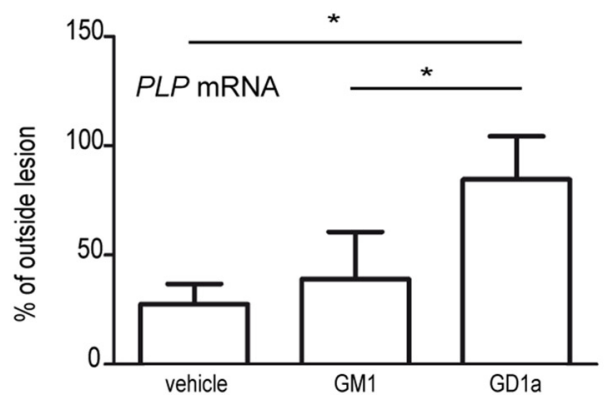

Figure 4. Exogenous addition of GD1a overcomes the inhibition of early OPC differentiation by aggregated fibronectin in vivo. $\boldsymbol{A}$, Schematic representation of the treatments as indicated in $\boldsymbol{B}$ - $\mathbf{G}$. Animals were fed with cuprizone for 5 weeks (wks) to allow for demyelination. At day 0, Fn aggregates (aFn; $1.5 \mu \mathrm{g}$ in $3 \mu$ l) were injected into the demyelinated corpus callosum, followed by treatment with vehicle (veh, ethanol) and the indicated gangliosides ( $10 \mu \mathrm{m}$ in $3 \mu \mathrm{l}$ ) at day 2 and day $3 . \boldsymbol{B}-\mathbf{G}, 5 \mathrm{~d}$ after aFn injection, the density of Olig2-positive ("oligodendrocyte lineage"; $\boldsymbol{B}, \boldsymbol{C}$ ), the amount of Ki67-positive and PDGF $\alpha$ R-positive ("OPC proliferation"; $\boldsymbol{D}, \boldsymbol{E}$ ), and PLP mRNA-positive ("differentiated oligodendrocytes"; $\boldsymbol{F}, \boldsymbol{G}$ ) cells were determined by immunohistochemistry $(\boldsymbol{B}-\boldsymbol{E})$ or in situ hybridization $(\boldsymbol{F}, \boldsymbol{G})$. Images in $\boldsymbol{B}, \boldsymbol{D}$, and $\boldsymbol{F}$ (in $\boldsymbol{F}$ the place of cannula is indicated with the dashed line) are representative images in the core of the $F n$ aggregate-injected demyelinated areas in the corpus callosum of five to six different animals. Scale bars: $\boldsymbol{B}, \boldsymbol{D}, 10 \mu \mathrm{m} ; \boldsymbol{F}, 100 \mu \mathrm{m}$. Data in $\boldsymbol{C}, \boldsymbol{E}$, and $\mathbf{G}$ are represented as the mean \pm SD, and statistical differences with vehicle-treated lesions, as assessed with a one-way ANOVA are indicated (Newman-Keuls post-test, ${ }^{*} p<0.05 ; n \geq 5$ ). Note the increase in 0lig2-positive, Ki67-positive/PDGF $\alpha$ R-positive and PLP mRNA-positive cells after treatment with ganglioside GD1a, but not ganglioside GM1, in aFn-injected demyelinated areas of the corpus callosum.

effective when OPCs or immature OLGs, which are grown on Fn, are transiently exposed to the ganglioside (Fig. 5E: OPCs, first (F) $72 \mathrm{~h}$ (F72h); immature OLGs, F24h, F48h), indicating that the effects of GDla on proliferation and maturation are likely separate events. Indeed, a $24 \mathrm{~h}$ exposure to GD1a of the postmitotic MBP-expressing OLGs, just before maturation, suffices to overcome the myelination-inhibiting effect of Fn in vitro [Fig. 5E; last (L) $24 \mathrm{~h}$ (L24h), $p=0.0005, n=7]$. OLG differentiation was unaffected at all conditions (Fig. 5D). Notably, exposure at the L24h resulted in the same effect as that obtained after a $96 \mathrm{~h}$ exposure at an earlier differentiation stage (Fig. $5 E, 96 \mathrm{~h} ; p=$ $0.0001, n=7$ ), suggesting a prolonged effectivity and implying that GDla is likely not (rapidly) degraded, which is consistent with the known long turnover rates of gangliosides (days to weeks). In fact, upon 24 and $96 \mathrm{~h}$ exposure, the levels of radioactively labeled GD1a were only reduced by $\sim 10-20 \%$, along with a 
A

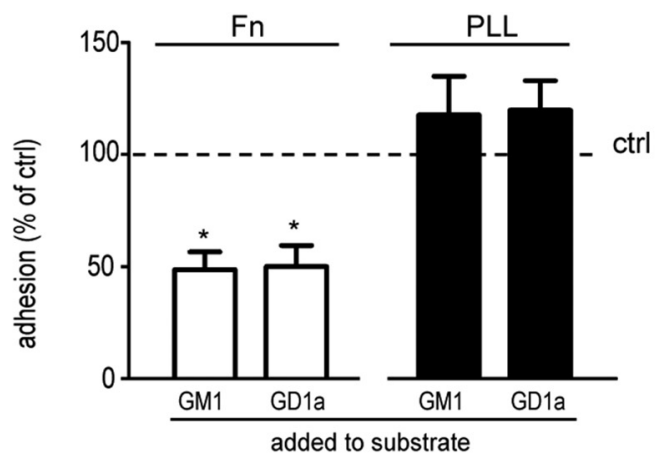

B

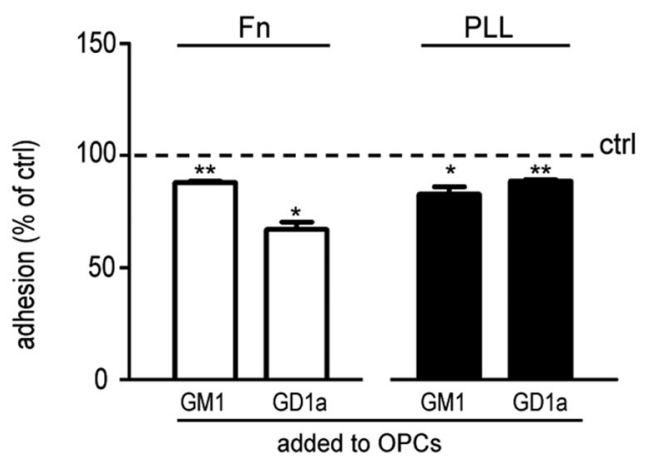

C

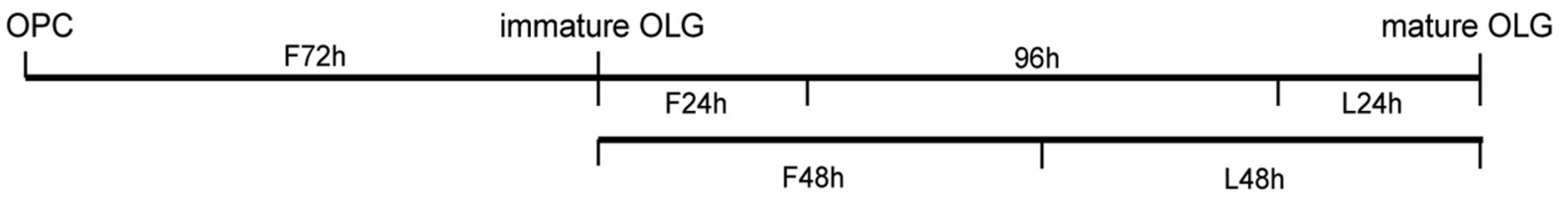

D

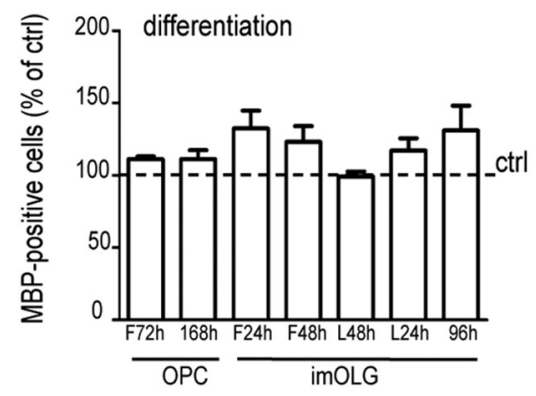

E

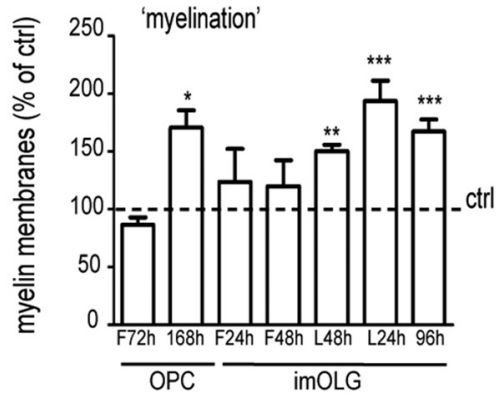

F

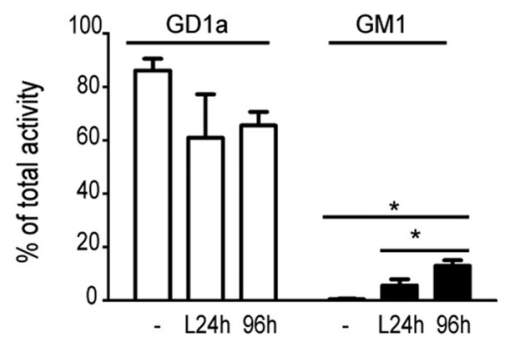

Figure 5. GD1a becomes effective in overcoming fibronectin-mediated inhibition of myelin membrane formation at a relatively late stage of $0 \mathrm{LG}$ maturation. $\boldsymbol{A}$, OPCS were plated on plasma Fnor PLL-coated 96-well plates that were pretreated with vehicle (ethanol, ctrl) or the indicated gangliosides (10 $\mu \mathrm{m}$ ). OPCs were allowed to adhere for $1 \mathrm{~h}$, after which the relative percentage of adherent cells was determined using a colorimetric assay. The horizontal line represents adherence to vehicle-treated substrates, which was set at $100 \%$ in each independent experiment. The percentage adherence of $O P C s$ on vehicle-treated PLL and Fn was $66.5 \pm 7.3 \%$ and $50.8 \pm 4.4 \%$, respectively. Statistical differences with $0 P(s$ cultured on the respective vehicle-treated substrate, as assessed with a one-sample $t$ test, are indicated (Fn, $\left.{ }^{*} p<0.05, n=3\right)$. Note that GD1a and GM1 pretreatment of Fn, but not of PLL, decreases the adhesion of compared with adhesion on vehicle-treated substrate. $\boldsymbol{B}$, Freshly isolated OPCs were pretreated for $30 \mathrm{~min}$ with vehicle (ethanol, ctrl) or the indicated gangliosides (10 $\mu \mathrm{m}$ ), plated on Fn- or PLL-coated 96 -well plates, and subjected to an adhesion assay $\left(\boldsymbol{A},{ }^{*} p<0.05,{ }^{* *} p<0.01, n=3\right)$. C, Schematic representation of the treatments indicated in $\boldsymbol{D}$ and $\boldsymbol{E}$. Upon differentiation of $0 \mathrm{PC}$ c cultured on Fn, cells were continuously or transiently exposed to GD1a at the indicated differentiation stage and duration. MBP immunocytochemistry was performed at the mature $0 \mathrm{LG}$ stage for all conditions. $\mathrm{h}=\mathrm{h}$. $\boldsymbol{D}, \boldsymbol{E}$, The number of MBP-positive cells (differentiation, $\boldsymbol{D}$ ) and the number of MBP-positive cells bearing myelin membranes ("myelination," $\boldsymbol{E}$ ) were assessed. Each bar represents the mean \pm SD of three independent experiments. In each experiment, the data of vehicle-treated cells was set at 100\% (horizontal line). The mean percentages of MBP-positive cells and MBP-positive cells bearing myelin membranes in vehicle-treated cells were $44.6 \pm 6.9 \%$ and $20.2 \pm 6.5 \%$, respectively. Statistical differences with vehicle-treated cells cultured as assessed with a one-sample $t$ test, are indicated $\left({ }^{*} p<0.05,{ }^{* *} p<0.01,{ }^{* * *} p<0.001, n \geq 3\right)$. Note that ganglioside GD1a overcomes Fn-mediated inhibition when present at late differentiation. $\boldsymbol{F}$, Immature 0 LGs and 0 LGs cultured on Fn at $6 \mathrm{~d}$ after initiating differentiation were treated with [ ${ }^{3} \mathrm{H}$ ]-GD1a for 96 and $24 \mathrm{~h}$, respectively. Total gangliosides were extracted and separated by TLC, and the percentage of total activity determined. " $0 \mathrm{~h}$ " is [ $\left.{ }^{3} \mathrm{H}\right]-G D 1$ a that was not exposed to cells. Each bar represents the mean \pm SD of three independent experiments. Statistical analysis as assessed with a one-way ANOVA are indicated (Newman-Keuls post-test, ${ }^{*} p<0.05, n=3$ ).

$5-15 \%$ increase in the level of GM1 (Fig. 5F; $p=0.019, n=3$ ), which is ineffective in reversing Fn inhibition (Figs. 1, 2, 3). To assess whether and which signaling pathways is/are potentially the target for GD1a in relieving the Fn myelination block (i.e., of relevance to OPC maturation), we performed an STK array.

GD1a overcomes inhibition of myelin membrane formation by fibronectin via activation of a PKA-signaling pathway STK activity profiles in OLGs, induced by GDla treatment, were generated with the STK PamChip peptide microarray system (Eriksson et al., 2014; Shi et al., 2016). The array contains 144 peptides, corresponding to activity-modulating phosphorylation sites of key signal transduction mediators, thus generating a network view on signal transduction activity. Ninety of the 144 pep- tides showed either an increase or a decrease of phosphorylation upon a 20 min exposure to GD1a (Fig. 6A). Peptides that differed significantly in the level of phosphorylation in vehicle-treated versus GD1a-treated OLGs are depicted in Table 1, and in Table 2 , the annotated upstream kinases, which potentially are responsible for the altered phosphorylation levels, are shown. Upon a 20 min exposure to GD1a, a set of 10 of 144 peptides was significantly phosphorylated, of which most (i.e., four peptide sequences) are annotated to the PKA signaling pathway (Fig. $6 A,{ }^{\star}$ ). Given that PKA has been implicated in the regulation of OPC differentiation (Raible and McMorris, 1990, 1993; Shiga et al., 2005; Syed et al., 2013), we next analyzed whether GDla can overcome the inhibition of OPC maturation on Fn via a PKAdependent mechanism. A PKA activity assay revealed that GD1a, 
A

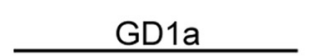

$0 \min 10 \min 20 \min 16 \mathrm{~h}$

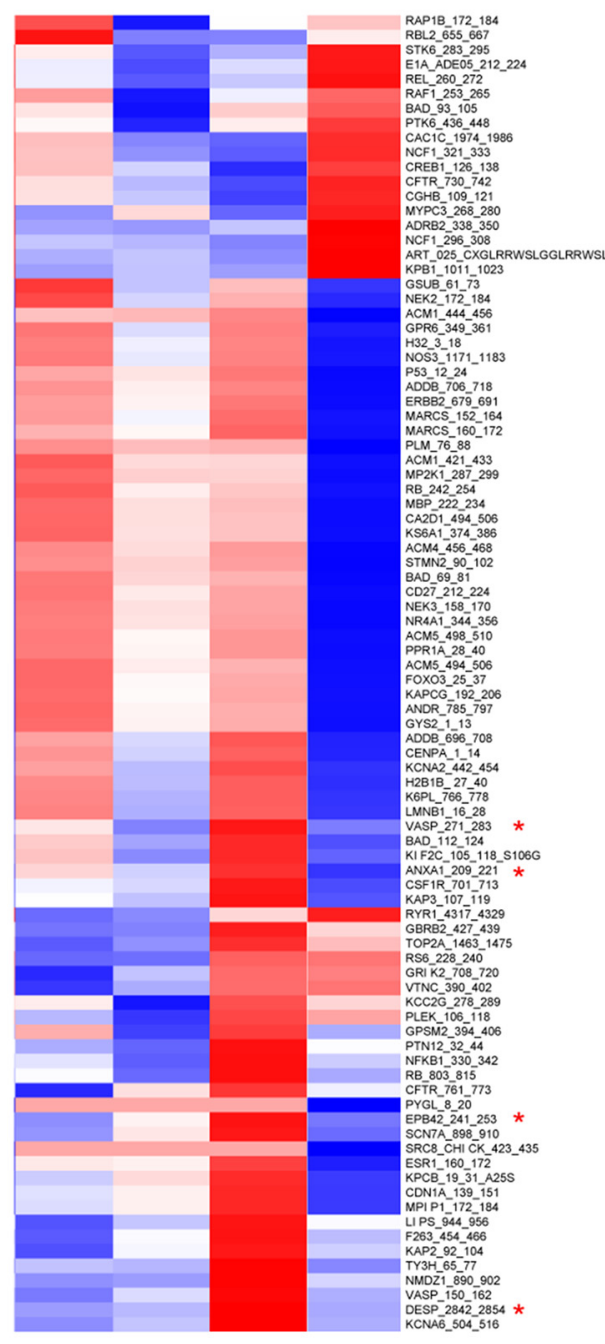

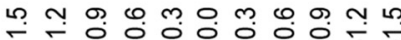

B

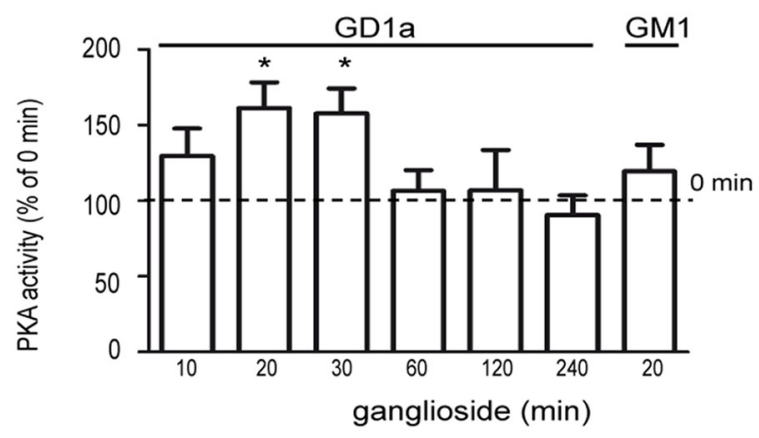

C

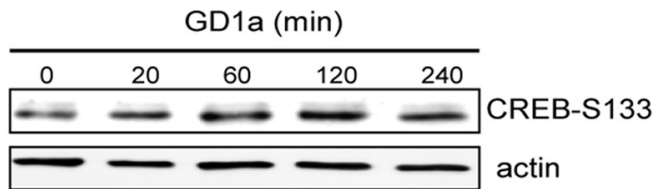

D

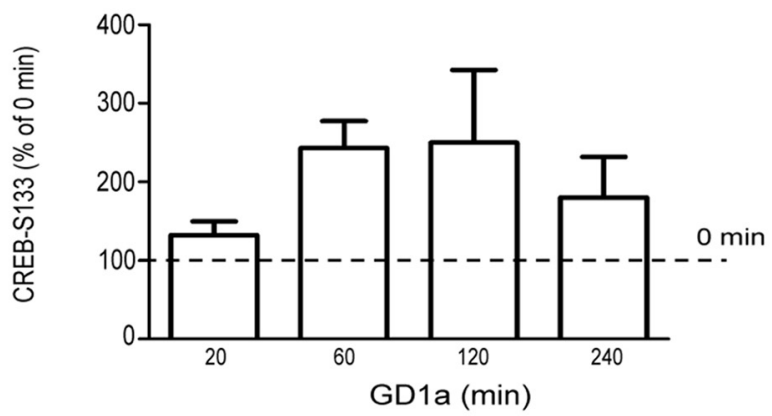

E

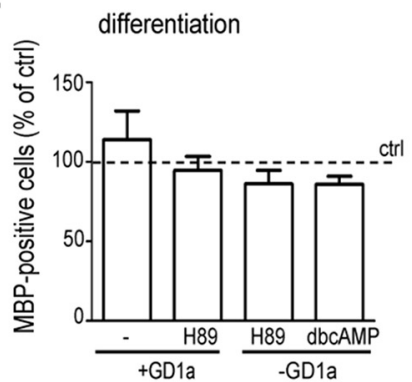

$\mathbf{F}$

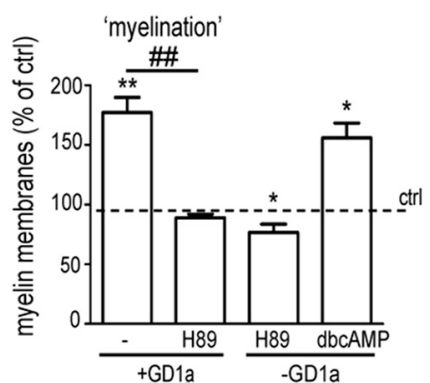

Figure 6. Exogenous addition of GD1a overcomes inhibition of myelin membrane formation by fibronectin via activation of a PKA-dependent pathway. A, 0 LGs cultured on Fn at $6 \mathrm{~d}$ after initiating differentiation were treated with ganglioside GD1a $(10 \mu \mathrm{m})$ for $10 \mathrm{~min}, 20 \mathrm{~min}$, or $16 \mathrm{~h}$ and subjected to a STK PamChip array. Clustering of normalized peptide phosphorylation signals. The phosphorylation signals were averaged ( $n=4$ for all conditions except $16 \mathrm{~h}(n=2))$. The heatmap shows the 90 of 144 peptides that were phosphorylated in at least one of the conditions compared with baseline phosphorylation $(T=0)$. Red and blue spots represent increased and decreased phosphorylation compared with the average phosphorylation. The peptide labels refer to the origin (protein and sequence) of the peptide sequences that are spotted on the PamChip array. A red asterisk $\left(^{*}\right)$ indicates peptides that are annotated to the upstream kinase PKA and that showed significant increased phosphorylation upon $20 \mathrm{~min}$ GD1a treatment compared with vehicle treatment. Other peptides that were significantly different phosphorylated upon GD1a treatment of OLGs ( $6 \mathrm{~d}$ in differentiation) compared with vehicle treatment are depicted in Table 1. B, OLGs cultured on Fn at $6 \mathrm{~d}$ after initiating differentiation were treated with gangliosides GD1a or GM1 (10 $\mu \mathrm{M}$ ) for the indicated time points and subjected to PKA activation assay. Each bar represents the mean \pm SD of three to five independent experiments. In each experiment, the data of $T=0$ min was set at $100 \%$ (horizontal line). Statistical differences with $T=0$ min as assessed with a one-sample test are indicated ( ${ }^{*} p<0.05, n \geq 3$ ). Note that GD1a activated PKA upon 20 - 30 min exposure, while PKA activity decreased to basal levels after $60 \mathrm{~min}$. $C, D, 0 \mathrm{LGs}$ cultured on $\mathrm{Fn}$ at $6 \mathrm{~d}$ after initiating differentiation were treated with ganglioside GD1a (10 $\mu \mathrm{M})$ for the indicated time points and subjected to Western blot analysis $(20 \mu \mathrm{g})$ using the CREB-S133 antibody. The CREB-S133 levels were quantified relative to the expression of the housekeeping protein actin (D). Each bar represents the mean $\pm S D$ of four independent experiments. In each experiment, the data of $T=0$ min was set at $100 \%$ (horizontal line). Statistical differences with $T=0$ min as assessed with a one-sample $t$ test, are indicated (nearly significant, $60 \mathrm{~min}, p=0.053, n=3) . E, F, 0 \mathrm{LGs}$ cultured on $\mathrm{Fn}$ at $6 \mathrm{~d}$ after initiating differentiation were treated with vehicle (ethanol, ctrl), H89 (20 $\mu \mathrm{M}$ ), dBcAMP $(1 \mathrm{~mm})$, and/or ganglioside GD1a $(10 \mu \mathrm{m})$ for $24 \mathrm{~h}$. H89 was added $1 \mathrm{~h}$ before GD1a. The number of MBP-positive cells (differentiation, $\boldsymbol{E}$ ) and the number of MBP-positive cells bearing myelin-like membranes (myelination; $\boldsymbol{F}$ ) were determined by MBP immunocytochemistry. Each bar represents the mean \pm SD of three to four independent experiments. In each experiment, the data from vehicle-treated cells were set at 100\% (horizontal line). The percentage of MBP-positive cells in vehicle-treated cells was $38.5 \pm 4.8 \%$, and the percentage of MBP-positive cells bearing myelin-like membranes was $17.9 \pm 3.6 \%$. Statistical differences with vehicle-treated cells cultured $\left(\boldsymbol{F}\right.$; one-sample $t$ test, ${ }^{*} p<0.05,{ }^{* *} p<0.01, n \geq 3$ ) and GD1a-treated cells ( $\boldsymbol{F}$; one-way ANOVA, Dunnett's post-test, \#\#\#p <0.0001, $n=3$ ) are indicated. Note that GD1a treatment of OLGs cultured on Fn activates PKA, phosphorylates CREB (S133) and that the PKA inhibitor H89 overcomes Fn-mediated inhibition of myelin membrane formation, while the activation of a PKA signaling pathway mimicked the effect of GD1a. 
Table 1. Peptides significantly different phosphorylated upon GD1a treatment of OLGs ( $6 \mathrm{~d}$ in differentiation) as compared to vehicle treatment

\begin{tabular}{|c|c|c|}
\hline Condition & Peptides up & Peptides down \\
\hline 0 vs $10 \mathrm{~min}$ & & GPSM2_394_406 \\
\hline \multirow[t]{10}{*}{0 vs $20 \mathrm{~min}$} & ANXA1_209_221 & CREB1_126_138 \\
\hline & BAD_112_124 & CDC2_154_169 \\
\hline & CDN1A_139_151 & \\
\hline & DESP_2842_2854 & \\
\hline & EPB42_241_253 & \\
\hline & FRAP_2443_2455 & \\
\hline & KCC2G_278_289 & \\
\hline & RS6_228_240 & \\
\hline & SCN7A_898_910 & \\
\hline & VASP_271_283 & \\
\hline \multirow[t]{8}{*}{0 vs $16 \mathrm{~h}$} & KCNA_438_450 & ACM1_421_433 \\
\hline & RYR1_4317_4329 & ANDR_785_797 \\
\hline & & ATM_1972_1984 \\
\hline & & CA2D1_494_506 \\
\hline & & CDK7_163_175 \\
\hline & & GYS2_1_13 \\
\hline & & KCNA2_422_454 \\
\hline & & NR4A1_344_356 \\
\hline \multirow[t]{16}{*}{$20 \min$ vs $16 \mathrm{~h}$} & ATM_1972_1984 & ACM1_421_433 \\
\hline & CFTR_730_742 & ACM1_444_456 \\
\hline & CREB1_126_138 & ACM4_456_468 \\
\hline & & ACM5_494_506 \\
\hline & & ANDR_785_797 \\
\hline & & ANXA1_209_221 \\
\hline & & BAD_112_124 \\
\hline & & CDC2_154_169 \\
\hline & & CDN1A_139_151 \\
\hline & & CENPA_1_14 \\
\hline & & ERBB2_679_691 \\
\hline & & GPSM2_394_406 \\
\hline & & GYS2_1-13 \\
\hline & & KCNA2_442_454 \\
\hline & & KCNA3_461_473 \\
\hline & & NR4A1_344_356 \\
\hline
\end{tabular}

but not GM1, activated PKA following a 20 min exposure, while after $60 \mathrm{~min}$ the PKA activity had decreased to basal levels (Fig. $6 B: 20 \mathrm{~min}, p=0.015 ; n=6 ; 30 \mathrm{~min}, p=0.025 ; n=5)$. To further explore the GDla-mediated signaling via PKA, we next analyzed its effect on the phosphorylation of the cellular transcription factor cAMP response element-binding protein (CREB), which is a downstream target of PKA. GD1a increased the S133 phosphorylation of CREB after a 60-120 min exposure to OLGs that were cultured on Fn (Fig. $6 C, D ; p=0.053, n=3$ ). Furthermore, H89, a PKA inhibitor, counteracted the effect of GD1a (Fig. 6F, \#\#\# $<0.0001 ; n=3$ ), while dBcAMP, a PKA activator, mimicked the effect of GDla on myelin formation in the presence of Fn (Fig. $6 F,{ }^{\star} p=0.020 ; n=4$ ). Differentiation remained unaltered (Fig. $6 E$ ). Together, these findings indicate that GD1a overcomes the inhibition of myelin membrane formation by Fn via a mechanism that relies on a PKA signaling pathway.

\section{Discussion}

When considering a remyelination-based therapy, both the cellular and molecular environment in MS lesions should be taken into account. Among others, perturbed degradation of ECM molecules contributes to a lack of OPC maturation in MS lesions (Back et al., 2005; Lau et al., 2012; Stoffels et al., 2013). Indeed, we previously demonstrated that aggregates of Fn are persistently present in MS lesions, which frustrates the differentiation of OPCs in demyelinated lesions and thereby impedes remyelina-
Table 2. Annotated upstream kinases potentially responsible for the altered phosphorylation levels upon GD1a treatment of OLGs

\begin{tabular}{|c|c|c|c|c|}
\hline Condition & Kinases up & Peptides & Kinases down & Peptides \\
\hline 0 vs $10 \mathrm{~min}$ & & & Not known & \\
\hline \multirow[t]{9}{*}{0 vs $20 \mathrm{~min}$} & PKA & 4 & CDK2/CDK7 & 1 \\
\hline & PKG/CGK & 2 & \multirow{8}{*}{$\begin{array}{l}\text { GSK3, RSK, } \\
\text { CAM-KII, CDK3, } \\
\text { SGK, DYRK3 }\end{array}$} & 1 \\
\hline & P70S6K & 2 & & \\
\hline & RSK group & 2 & & \\
\hline & PKB group & 2 & & \\
\hline & PKC $-\alpha$ & 1 & & \\
\hline & PIM1 & 1 & & \\
\hline & CAM-KII & 1 & & \\
\hline & AMPK & 1 & & \\
\hline \multirow[t]{4}{*}{$0 \mathrm{vs} 16 \mathrm{~h}$} & & & PKB group & 2 \\
\hline & & & ATM & 1 \\
\hline & & & CDK2/CDK7 & 1 \\
\hline & & & PKA group & 1 \\
\hline \multirow[t]{7}{*}{$20 \mathrm{~min}$ vs $16 \mathrm{~h}$} & ATM & 1 & PKA group & 2 \\
\hline & PKA group, PKG/cGK group & 1 & PKB group & 3 \\
\hline & GSK3 group, RSK group, CDK3, & 1 & PKC group & 1 \\
\hline & CAM-KII group, CAM-KIV, & & RSK group & 1 \\
\hline & DYRK3, MAPKAP2, SGK group & & CDK2/CDK7 & 1 \\
\hline & & & PIM1 & 1 \\
\hline & & & Aurora A/B & 1 \\
\hline
\end{tabular}

tion (Stoffels et al., 2013). To trigger OPC maturation and subsequent remyelination within the lesion, a minimal therapeutic requirement appears to be either a lesional clearance of the aggregates as such or a circumvention or suppression of their impeding effects on myelin assembly. Our present findings demonstrate that the exogenous addition of ganglioside GD1a overruled the devastating effect of the presence of Fn aggregates on OPC maturation. The underlying mechanism appears related to a specific GD1a-dependent activation of a PKA signaling pathway. Thus, exogenously added GDla, but not other gangliosides tested, antagonizes the inhibitory effect of (aggregated) Fn on myelin membrane formation in primary OLG monocultures and DRGN-OLG cocultures and remyelination in demyelinated cerebellar slice cultures. The significance of the in vitro data was corroborated in the cuprizone demyelination-remyelination model. In this model, we managed to mimic a transient local Fn aggregate-containing lesion in the demyelinated corpus callosum that allows study of the effect of GD1a on OPC proliferation and early differentiation. Injection of GDla into this Fn aggregatecontaining lesion increased the number of OLG lineage cells, which reflects an increased OPC proliferation and, based on our observations obtained in OLG monocultures, presumably a decreased migration rather than an increased survival. In addition, the number of PLP mRNA-containing cells was enhanced in GD1a-treated lesions, but not GM1-treated lesions, which is consistent with an enhanced OPC differentiation. Evidently, the present data support the notion that targeted delivery of GD1a to Fn (aggregate)-containing MS lesions may act as a potential novel molecular and therapeutic tool to induce OPC proliferation and maturation and to overcome remyelination failure.

In the CNS, endogenous GD1a is prominently expressed in neurons (Schnaar and Lopez, 2009), while conflicting findings about its presence in OLG lineage cells have been reported (Satoh et al., 1996; Marconi et al., 2005; Silajdzić et al., 2009). Among others, gangliosides actively participate in the organization of membrane signaling microdomains (Sonnino and Prinetti, 2010), for example, by directing adhesion receptors to discrete areas for optimal interaction with the opposing membrane. Both spatial 
and temporal formation of membrane microdomains play a key role in myelination (Baron et al., 2005; Aureli et al., 2015), while oligodendroglial membrane microdomains are perturbed by Fn (Maier et al., 2005; Baron et al., 2014). More specifically, in cells grown on an Fn substrate, the galactolipid sulfatide is excluded from membrane microdomains, which in turn precludes the propagation of myelination-promoting laminin-2 signaling (Baron et al., 2014). Moreover, in MS lesions, an altered membrane microdomain distribution of oligodendroglial NF155 and sulfatide is observed, compared with the distribution of these components in rafts, and isolated from healthy white matter (Maier et al., 2005, 2007). It is therefore tempting to suggest that exogenously added GD1a modulates perturbed membrane microdomains, which were induced by Fn (aggregates) in OLGs. In fact, exogenously added gangliosides may alter the lateral membrane distribution (Simons et al., 1999), while exogenously added GD1a readily integrates into OLG membrane microdomains (Heffer-Lauc et al., 2005). The thus restored membrane microdomain integrity might re-establish the correct PKAmediated signaling environment that is required for OPC maturation. Consistently on Fn PKA, activation mimics the (re)myelination stimulus of GD1a, while PKA inhibition blocks the effect of GD1a. Specifically, in OLGs cultured on Fn GD1a exposure activated PKA, causing phosphorylation of its downstream target CREB. Several lines of evidence indicate that the elevation of cAMP levels, the ensuing activation of PKA, and CREB phosphorylation are necessary events in regulating OLG maturation and myelin protein expression in primary OLGs (Raible and McMorris, 1990, 1993; Sato-Bigbee and DeVries, 1996; Shiga et al., 2005). Furthermore, inhibitors of cAMP-hydrolyzing phosphodiesterases induce the expression of myelin-specific components (Medina-Rodríguez et al., 2013; Syed et al., 2013), while a regulatory control mechanism for PKA activity has been described for a timed progression of the OLG lineage (Baron et al., 1998; Simon et al., 2016). The current work thus leads to a scenario in which (1) Fn may hinder the activation of a PKA signaling pathway that is essential for OPC maturation, while (2) this impediment can be overcome by exogenous addition of GDla. However, the coinvolvement of the other annotated serine/threonine kinases (Table 2), such as CaMKII (Waggener et al., 2013) or p70S6K (Baron et al., 2000; Michel et al., 2015) cannot be excluded. Strikingly, MAPK, a downstream target of PKA in OLGs and shown to be implicated in early OPC differentiation on inert substrates, among others, by the phosphorylation of CREB (Baron et al., 2000; Fragoso et al., 2007; Guardiola-Diaz et al., 2012; Syed et al., 2013), was not identified with the STK array as an immediate kinase, activated by GD1a on Fn. However, whether MAPK may be critical for the effect of GDla on Fn remains to be determined. In addition, given the polarized nature of OLGs, it is of interest that PKA is also involved in the biogenesis of polarized membrane domains in epithelial cells; the activation of PKA facilitates exocytosis, reduces (apical) endocytosis, and modulates transcytosis (Wojtal et al., 2008). Given our previous studies showing that polarized transport in OLGs becomes severely impaired in cells cultured on Fn (Baron et al., 2014; Sisková et al., 2006), it seems reasonable to speculate that GDla and the subsequent activation of PKA restore polarized transport and hence myelin biogenesis in OLGs cultured of Fn.

Without effective therapeutics in treating MS, it is appealing to consider GD1a as a novel tool in promoting OPC proliferation and maturation, and thereby remyelination, in MS lesions. GD1a acts in vitro during a late step in OLG maturation to induce myelin membrane formation, but can be added independent of the developmental stage of OLG maturation. In addition, GD1a does not affect myelin formation on either inert PLL or laminin-2, suggesting that its effect is Fn dependent. These features may all bear therapeutic relevance to the treatment of MS. For example, in MS lesions, a significant fraction of OPCs remains quiescent (Lucchinetti et al., 1999; Chang et al., 2002; Kuhlmann et al., 2008), among others due to the presence of Fn aggregates (Stoffels et al., 2013). Here, GD1a may act to expand OPCs and generate remyelinating OLGs. In fact, in postmortem MS lesions of patients with a relative short disease duration, mature OLGs that make contact with surrounding demyelinated axons are a prominent feature (Wolswijk, 2000; Chang et al., 2002; Kuhlmann et al., 2008). GD1a may act on these cells to boost OPC maturation. In chronic MS lesions, the presence of immature OLGs is limited while OPC proliferation is a rare event (Wolswijk, 1998; Kuhlmann et al., 2008). However, based on the present findings and the presence of Fn in chronic MS lesions, GDla may enhance the proliferative capacity of OPCs in these lesions. In addition, since the presence of immature OLGs is increased in lesions with high OPC densities (Wolswijk, 2002), OLG maturation may improve. Together, the robust effect of exogenous GDla, evoked by the activation of a PKA signaling pathway, on myelin membrane formation in the presence of Fn, and proliferation, in conjunction with the presence of either OPCs and/or immature OLGs and Fn (aggregates) in MS lesions, points to a novel treatment option that may boost the proliferation and maturation of resident OPCs and thereby overcome remyelination failure in MS lesions.

\section{References}

Aureli M, Grassi S, Prioni S, Sonnino S, Prinetti A (2015) Lipid membrane domains in the brain. Biochim Biophys Acta 1851:1006-1016. CrossRef Medline

Back SA, Tuohy TM, Chen H, Wallingford N, Craig A, Struve J, Luo NL, Banine F, Liu Y, Chang A, Trapp BD, Bebo BF Jr, Rao MS, Sherman LS (2005) Hyaluronan accumulates in demyelinated lesions and inhibits oligodendrocyte progenitor maturation. Nat Med 11:966-972. CrossRef Medline

Baron W, de Jonge JC, de Vries H, Hoekstra D (1998) Regulation of oligodendrocyte differentiation: protein kinase $\mathrm{C}$ activation prevents differentiation of O2A progenitor cells toward oligodendrocytes. Glia 22:121-129. CrossRef Medline

Baron W, Metz B, Bansal R, Hoekstra D, de Vries H (2000) PDGF and FGF-2 signaling in oligodendrocyte progenitor cells: regulation of proliferation and differentiation by multiple intracellular signaling pathways. Mol Cell Neurosci 15:314-329. CrossRef Medline

Baron W, Colognato H, ffrench-Constant C (2005) Integrin-growth factor interactions as regulators of oligodendroglial development and function. Glia 49:467-479. CrossRef Medline

Baron W, Bijlard M, Nomden A, de Jonge JC, Teunissen CE, Hoekstra D (2014) Sulfatide-mediated control of extracellular matrix-dependent oligodendrocyte maturation. Glia 62:927-942. CrossRef Medline

Bsibsi M, Nomden A, van Noort JM, Baron W (2012) Toll-like receptors 2 and 3 agonists differentially affect oligodendrocyte survival, differentiation, and myelin membrane formation. J Neurosci Res 90:388-398. CrossRef Medline

Buttery PC, ffrench-Constant C (1999) Laminin-2/integrin interactions enhance myelin membrane formation by oligodendrocytes. Mol Cell Neurosci 14:199-212. CrossRef Medline

Chang A, Tourtellotte WW, Rudick R, Trapp BD (2002) Premyelinating oligodendrocytes in chronic lesions of multiple sclerosis. N Engl J Med 346:165-173. CrossRef Medline

Chari DM, Zhao C, Kotter MR, Blakemore WF, Franklin RJ (2006) Corticosteroids delay remyelination of experimental demyelination in the rodent central nervous system. J Neurosci Res 83:594-605. CrossRef Medline

Compston A, Coles A (2008) Multiple sclerosis. Lancet 372:1502-1517. CrossRef Medline 
Eriksson A, Kalushkova A, Jarvius M, Hilhorst R, Rickardson L, Kultima HG, de Wijn R, Hovestad L, Fryknäs M, Öberg F, Larsson R, Parrow V, Höglund M (2014) AKN-028 induces cell cycle arrest, downregulation of Myc associated genes and dose dependent reduction of tyrosine kinase activity in acute myeloid leukemia. Biochem Pharmacol 87:284-291. CrossRef Medline

Espitia Pinzon N, Sanz-Morello B, Brevé JJ, Bol JG, Drukarch B, Bauer J, Baron W, van Dam AM (2017) Astrocyte-derived tissue Transglutaminase affects fibronectin deposition, but not aggregation, during cuprizoneinduced demyelination. Sci Rep 7:40995. CrossRef Medline

Fragoso G, Haines JD, Roberston J, Pedraza L, Mushynski WE, Almazan G (2007) p38 mitogen-activated protein kinase is required for central nervous system myelination. Glia 55:1531-1541. CrossRef Medline

Franklin RJ, ffrench-Constant C (2008) Remyelination in the CNS: from biology to therapy. Nat Rev Neurosci 9:839-855. CrossRef Medline

Gerdes J, Schwab U, Lemke H, Stein H (1983) Production of a mouse monoclonal antibody reactive with a human nuclear antigen associated with cell proliferation. Int J Cancer 31:13-20. CrossRef Medline

Goldschmidt T, Antel J, König FB, Brück W, Kuhlmann T (2009) Remyelination capacity of the MS brain decreases with disease chronicity. Neurology 72:1914-1921. CrossRef Medline

Guardiola-Diaz HM, Ishii A, Bansal R (2012) Erk1/2 MAPK and mTOR signaling sequentially regulates progression through distinct stages of oligodendrocyte differentiation. Glia 60:476-486. CrossRef Medline

Gudi V, Gingele S, Skripuletz T, Stangel M (2014) Glial response during cuprizone-induced de- and remyelination in the CNS: lessons learned. Front Cell Neurosci 8:73. CrossRef Medline

Heffer-Lauc M, Lauc G, Nimrichter L, Fromholt SE, Schnaar RL (2005) Membrane redistribution of gangliosides and glycosylphosphatidylinositolanchored proteins in brain tissue sections under conditions of lipid raft isolation. Biochim Biophys Acta 1686:200-208. CrossRef Medline

Hibbits N, Yoshino J, Le TQ, Armstrong RC (2012) Astrogliosis during acute and chronic cuprizone demyelination and implications for remyelination. ASN Neuro 4:393-408. CrossRef Medline

Irvine KA, Blakemore WF (2008) Remyelination protects axons from demyelination-associated axon degeneration. Brain 131:1464-1477. CrossRef Medline

Kuhlmann T, Miron V, Cuo Q, Wegner C, Antel J, Brück W (2008) Differentiation block of oligodendroglial progenitor cells as a cause of remyelination failure in chronic multiple sclerosis. Brain 131:1749-1758. CrossRef Medline

Lafrenaye AD, Fuss B (2010) Focal adhesion kinase can play unique and opposing roles in regulating the morphology of differentiating oligodendrocytes. J Neurochem 115:269-282. CrossRef Medline

Lau LW, Keough MB, Haylock-Jacobs S, Cua R, Döring A, Sloka S, Stirling DP, Rivest S, Yong VW (2012) Chondroitin sulfate proteoglycans in demyelinated lesions impair remyelination. Ann Neurol 72:419-432. CrossRef Medline

Lopez PH, Schnaar RL (2009) Gangliosides in cell recognition and membrane protein regulation. Curr Opin Struct Biol 19:549-557. CrossRef Medline

Lucchinetti C, Brück W, Parisi J, Scheithauer B, Rodriguez M, Lassmann H (1999) A quantitative analysis of oligodendrocytes in multiple sclerosis lesions. A study of 133 cases. Brain 122:2279-2295. CrossRef Medline

Maier O, van der Heide T, van Dam AM, Baron W, de Vries H, Hoekstra D (2005) Alteration of the extracellular matrix interferes with raft association of neurofascin in oligodendrocytes. Potential significance for multiple sclerosis? Mol Cell Neurosci 28:390-401. CrossRef Medline

Maier O, Baron W, Hoekstra D (2007) Reduced raft-association of NF155 in active MS-lesions is accompanied by the disruption of the paranodal junction. Glia 55:885-895. CrossRef Medline

Marconi S, De Toni L, Lovato L, Tedeschi E, Gaetti L, Acler M, Bonetti B (2005) Expression of gangliosides on glial and neuronal cells in normal and pathological adult human brain. J Neuroimmunol 170:115-121. CrossRef Medline

Medina-Rodríguez EM, Arenzana FJ, Pastor J, Redondo M, Palomo V, García de Sola R, Gil C, Martínez A, Bribián A, de Castro F (2013) Inhibition of endogenous phosphodiesterase 7 promotes oligodendrocyte precursor differentiation and survival. Cell Mol Life Sci 70:3449-3462. CrossRef Medline

Merzak A, Koochekpour S, Pilkington GJ (1995) Adhesion of human glioma cell lines to fibronectin, laminin, vitronectin and collagen I is mod- ulated by gangliosides in vitro. Cell Adhes Commun 3:27-43. CrossRef Medline

Michel K, Zhao T, Karl M, Lewis K, Fyffe-Maricich SL (2015) Translational control of myelin basic protein expression by ERK 2 MAP kinase regulates timely remyelination in the adult brain. J Neurosci 35:78507865. CrossRef Medline

Miron VE, Ludwin SK, Darlington PJ, Jarjour AA, Soliven B, Kennedy TE, Antel JP (2010) Fingolimod (FTY720) enhances remyelination following demyelination of organotypic cerebellar slices. Am J Pathol 176:26822694. CrossRef Medline

Münzel EJ, Jolanda Münzel E, Williams A (2013) Promoting remyelination in multiple sclerosis-recent advances. Drugs 73:2017-2029. CrossRef Medline

Natarajan C, Yao SY, Sriram S (2016) TLR3 agonist poly-IC induces IL-33 and promotes myelin repair. PLoS One 11:e0152163. CrossRef Medline

Raible DW, McMorris FA (1990) Induction of oligodendrocyte differentiation by activators of adenylate cyclase. J Neurosci Res 27:43-46. CrossRef Medline

Raible DW, McMorris FA (1993) Oligodendrocyte differentiation and progenitor cell proliferation are independently regulated by cyclic AMP. J Neurosci Res 34:287-294. CrossRef Medline

Sato-Bigbee C, DeVries GH (1996) Treatment of oligodendrocytes with antisense deoxyoligonucleotide directed against CREB mRNA: effect on the cyclic AMP-dependent induction of myelin basic protein expression. J Neurosci Res 46:98-107. CrossRef Medline

Satoh JI, Tai T, Kim SU (1996) Differential expression of gangliosides and galactolipids in fetal human oligodendrocytes and astrocytes in culture. Brain Res Dev Brain Res 93:172-181. CrossRef Medline

Schnaar RL, Lopez PH (2009) Myelin-associated glycoprotein and its axonal receptors. J Neurosci Res 87:3267-3276. CrossRef Medline

Senn HJ, Sellin S, Fitzke E, Stehle T, Häussinger D, Wieland H, Gerok W (1992) Biosynthesis and excretion of gangliosides by the isolated perfused rat liver. Eur J Biochem 205:809-814. CrossRef Medline

Shi J, Sharif S, Ruijtenbeek R, Pieters RJ (2016) Activity based highthroughput screening for novel O-GlcNAc transferase substrates using a dynamic peptide microarray. PLoS One 11:e0151085. CrossRef Medline

Shiga H, Asou H, Ito E (2005) Advancement of differentiation of oligodendrocyte progenitor cells by a cascade including protein kinase A and cyclic AMP-response element binding protein. Neurosci Res 53:436-441. CrossRef Medline

Silajdzić E, Willison HJ, Furukawa K, Barnett SC (2009) In vitro analysis of glial cell function in ganglioside-deficient mice. J Neurosci Res 87:24672483. CrossRef Medline

Simon K, Hennen S, Merten N, Blättermann S, Gillard M, Kostenis E, Gomeza J (2016) The Orphan G Protein-coupled Receptor GPR17 negatively regulates oligodendrocyte differentiation via $\mathrm{G} \alpha \mathrm{i} / \mathrm{o}$ and its downstream effector molecules. J Biol Chem 291:705-718. CrossRef Medline

Simons M, Friedrichson T, Schulz JB, Pitto M, Masserini M, Kurzchalia TV (1999) Exogenous administration of gangliosides displaces GPI-anchored proteins from lipid microdomains in living cells. Mol Biol Cell 10:3187-3196. CrossRef Medline

Sisková Z, Baron W, de Vries H, Hoekstra D (2006) Fibronectin impedes "myelin" sheet-directed flow in oligodendrocytes: a role for a beta 1 integrin-mediated PKC signaling pathway in vesicular trafficking. Mol Cell Neurosci 33:150-159. CrossRef Medline

Sisková Z, Yong VW, Nomden A, van Strien M, Hoekstra D, Baron W (2009) Fibronectin attenuates process outgrowth in oligodendrocytes by mislocalizing MMP-9 activity. Mol Cell Neurosci 42:234-242. CrossRef Medline

Sonnino S, Prinetti A (2010) Gangliosides as regulators of cell membrane organization and functions. Adv Exp Med Biol 688:165-184. CrossRef Medline

Stancic M, Slijepcevic D, Nomden A, Vos MJ, de Jonge JC, Sikkema AH, Gabius HJ, Hoekstra D, Baron W (2012) Galectin-4, a novel neuronal regulator of myelination. Glia 60:919-935. CrossRef Medline

Stoffels JM, de Jonge JC, Stancic M, Nomden A, van Strien ME, Ma D, Sisková, Maier O, ffrench-Coanstant C, Franklin RJ, Hoekstra D, Zhao C, Baron W (2013) Fibronectin aggregation in multiple sclerosis lesions impairs remyelination. Brain 136:116-131. CrossRef Medline

Stoffels JM, Hoekstra D, Franklin RJ, Baron W, Zhao C (2015) The EIIIA 
domain from astrocyte-derived fibronectin mediates proliferation of oligodendrocyte progenitor cells following CNS demyelination. Glia 63: 242-256. CrossRef Medline

Syed YA, Baer A, Hofer MP, González GA, Rundle J, Myrta S, Huang JK, Zhao C, Rossner MJ, Trotter MW, Lubec G, Franklin RJ, Kotter MR (2013) Inhibition of phosphodiesterase-4 promotes oligodendrocyte precursor cell differentiation and enhances CNS remyelination. EMBO Mol Med 5:1918-1934. CrossRef Medline

Waggener CT, Dupree JL, Elgersma Y, Fuss B (2013) CaMKII $\beta$ regulates oligodendrocyte maturation and CNS myelination. J Neurosci 33:1045310458. CrossRef Medline

Wang X, Sun P, Al-Qamari A, Tai T, Kawashima I, Paller AS (2001) Carbohydrate-carbohydrate binding of ganglioside to integrin alpha(5) modulates alpha(5)beta(1) function. J Biol Chem 276:8436-8444. CrossRef Medline
Winkelmann A, Loebermann M, Reisinger EC, Hartung HP, Zettl UK (2016) Disease-modifying therapies and infectious risks in multiple sclerosis. Nat Rev Neurol 12:217-233. CrossRef Medline

Wojtal KA, Hoekstra D, van Ijzendoorn SC (2008) cAMP-dependent protein kinase $\mathrm{A}$ and the dynamics of epithelial cell surface domains: moving membranes to keep in shape. Bioessays 30:146-155. CrossRef Medline

Wolswijk G (1998) Chronic stage multiple sclerosis lesions contain a relatively quiescent population of oligodendrocyte precursor cells. J Neurosci 18:601-609. Medline

Wolswijk G (2000) Oligodendrocyte survival, loss and birth in lesions of chronic-stage multiple sclerosis. Brain 123:105-115. CrossRef Medline

Wolswijk G (2002) Oligodendrocyte precursor cells in the demyelinated multiple sclerosis spinal cord. Brain 125:338-349. CrossRef Medline 